\title{
FRACTIONAL SNOW-COVER MAPPING THROUGH ARTIFICIAL NEURAL NETWORK ANALYSIS OF MODIS SURFACE REFLECTANCE
}

\author{
A Thesis \\ by \\ ILIYANA DANCHEVA DOBREVA
}

\begin{abstract}
Submitted to the Office of Graduate Studies of Texas A\&M University in partial fulfillment of the requirements for the degree of

MASTER OF SCIENCE
\end{abstract}

December 2009

Major Subject: Geography 


\title{
FRACTIONAL SNOW-COVER MAPPING THROUGH ARTIFICIAL NEURAL NETWORK ANALYSIS OF MODIS SURFACE REFLECTANCE
}

\author{
A Thesis \\ by \\ ILIYANA DANCHEVA DOBREVA
}

\begin{abstract}
Submitted to the Office of Graduate Studies of Texas A\&M University

in partial fulfillment of the requirements for the degree of

MASTER OF SCIENCE
\end{abstract}

\begin{abstract}
Approved by:
Co-Chairs of Committee, Andrew G. Klein

Anthony M. Filippi

Committee Member, Yoonsuck Choe

Head of Department, Douglas J. Sherman
\end{abstract}

December 2009

Major Subject: Geography 


\author{
ABSTRACT \\ Fractional Snow-Cover Mapping Through Artificial Neural Network Analysis of \\ MODIS Surface Reflectance. (December 2009) \\ Iliyana Dancheva Dobreva, B.A., Concord University \\ Co-Chairs of Advisory Committee: Dr. Andrew G. Klein \\ Dr. Anthony M. Filippi
}

Accurate areal measurements of snow-cover extent are important for hydrological and climate modeling. The traditional method of mapping snow cover is binary where a pixel is approximated to either snow-covered or snow-free. Fractional snow cover (FSC) mapping achieves a more precise estimate of areal snow-cover extent by determining the fraction of a pixel that is snow-covered. The two most common FSC methods using Moderate Resolution Imaging Spectroradiometer (MODIS) images are linear spectral unmixing and the empirical Normalized Difference Snow Index (NDSI) method. Machine learning is an alternative to these approaches for estimating FSC, as Artificial Neural Networks (ANNs) have been used for estimating the subpixel abundances of other surfaces. The advantages of ANNs over the other approaches are that they can easily incorporate auxiliary information such as land-cover type and are capable of learning nonlinear relationships between surface reflectance and snow fraction. ANNs are especially applicable to mapping snow-cover extent in forested areas where spatial mixing of surface components is nonlinear. 
This study developed an ANN approach to snow-fraction mapping. A feedforward ANN was trained with backpropagation to estimate FSC from MODIS surface reflectance, NDSI, Normalized Difference Vegetation Index (NDVI) and land cover as inputs. The ANN was trained and validated with high spatial-resolution FSC derived from Landsat Enhanced Thematic Mapper Plus (ETM+) binary snow-cover maps. ANN achieved best result in terms of extent of snow-covered area over evergreen forests, where the extent of snow cover was slightly overestimated. Scatter plot graphs of the ANN and reference FSC showed that the neural network tended to underestimate snow fraction in high FSC and overestimate it in low FSC. The developed ANN compared favorably to the standard MODIS FSC product with the two methods estimating the same amount of total snow-covered area in the test scenes. 


\section{ACKNOWLEDGEMENTS}

I would like to thank the Texas A\&M University Geography department for the great academic environment and my committee for their support of the project. In particular, I would like to thank Dr. Andrew Klein for guiding every step of the project; Dr. Anthony Filippi for the opportunities to work on other remote-sensing and neuralnetwork projects; and Dr. Yoonsuck Choe for the interesting and informative Artificial Intelligence and Neural Networks classes.

Thanks also to the students in the Studies of the Cryosphere research group who patiently listen to the details of the project and provided helpful feedback: Zhaohui Chi, Joni Kincaid, LaDonna Latterman and Jeniffer Morris.

Finally, thanks to my husband and my mother for their encouragement and support. 
TABLE OF CONTENTS

Page

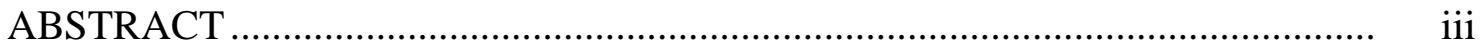

ACKNOWLEDGEMENTS _............................................................................. v

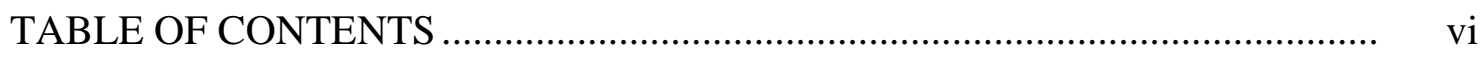

LIST OF FIGURES ................................................................................... viii

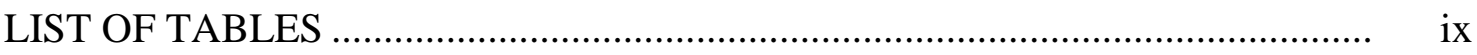

1. INTRODUCTION ...............................................................................

1.1 Importance of Snow-Cover Research ……………………………........ 1

1.2 Study Purpose and Objectives................................................................ 3

2. LITERATURE REVIEW ........................................................................

2.1 Snow-Cover-Extent Mapping ............................................................... $\quad 7$

$2.2 \quad$ Fractional Snow Cover Mapping …………………………………..... $\quad 10$

2.2.1 Linear Mixture Analysis.......................................................... 11

2.2.2 Empirical Approaches to Fractional Snow Cover Mapping ..... 18

2.3 Artificial Neural Networks Approach to Snow Fraction Mapping ...... 20

2.3.1 Advantages of Artificial Neural Networks................................ 22

2.3.2 Artificial Neural Networks in Subpixel Studies........................ 22

2.3.3 Artificial Neural Networks in Snow Studies.............................. 23

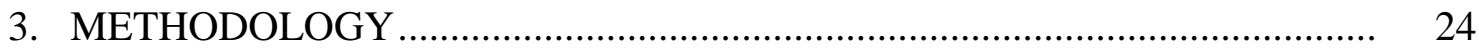

3.1 Artificial Neural Networks................................................................ 24

3.1.1 The Neuron......................................................................... 24

3.1.2 Artificial Neural Network Architecture ……………………..... 27

3.1.3 Learning ................................................................................ 28

3.1.4 Properties of Artificial Neural Network in Current Study ........ $\quad 29$

3.2 Reference Fractional Snow Cover Maps................................................ 32

3.2.1 Landsat ETM+ Scene Selection and Preprocessing.................. 33

3.2.2 Landsat Snow Maps ................................................................. 36 
3.3 MODIS Preprocessing..................................................................... 38

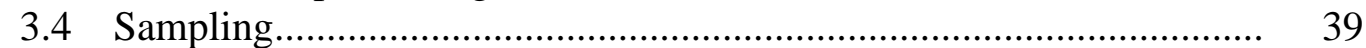

3.4.1 Refinement of Samples and Network Training........................ 42

3.5 Application Software Used in the Study ............................................... 43

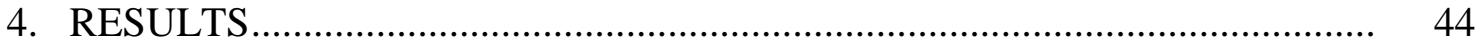

4.1 Overall Mapping Accuracy ………………………………………….... 44

4.2 Mapping Accuracy by Land Cover ....................................................... 56

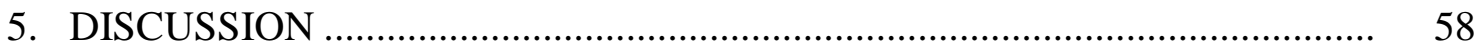

5.1 Overall Performance of ANN .............................................................. 58

5.2 Comparison to MODIS Snow-Cover Products ................................... 58

5.3 Comparison to Linear Spectral Unmixing ………………………....... 60

5.4 Error Analysis ................................................................................. 61

6. CONCLUSIONS AND FUTURE DIRECTIONS ............................................... 64

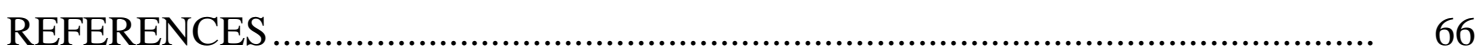

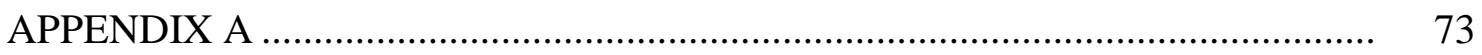

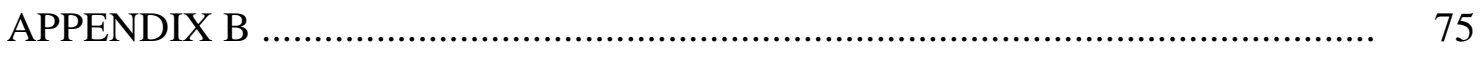

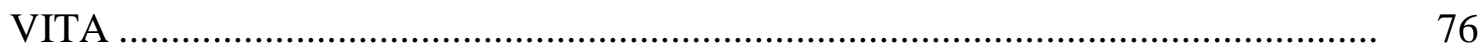




\section{LIST OF FIGURES}

FIGURE Page

$1 \quad$ Training and test Landsat scenes are located in North America ................ 6

2 Nonlinear model of a neuron.............................................................. 25

3 Transfer functions...................................................................... 26

$4 \quad$ A multi-layer feed-forward ANN ........................................................ 28

$5 \quad$ Resampling to MODIS resolution.................................................... 37

$6 \quad$ Stratified random sampling per land cover and snow fraction.................. 40

$7 \quad$ Sample points used in final ANN ...................................................... 41

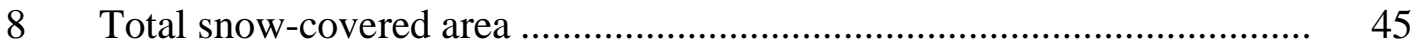

9 Difference in percentage of snow-covered area .................................. 46

10 Scatter plots of test scene A ........................................................... 47

11 Scatter plots of test scene B............................................................. 48

12 Scatter plots of test scene C.............................................................. 48

13 ANN results of the network over Test Scene A .................................... 50

14 ANN results of the network over Test Scene B .................................... 51

15 ANN results of the network over Test Scene C ................................... 52

16 Error maps of test scene A …............................................................... 53

17 Error maps of test scene B............................................................ 54

18 Error maps of test scene C................................................................. 55

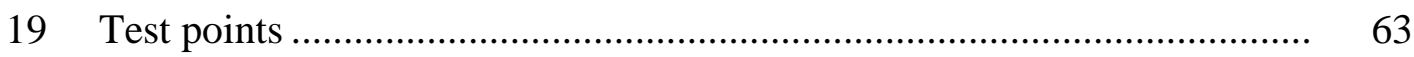




\section{LIST OF TABLES}

TABLE Page

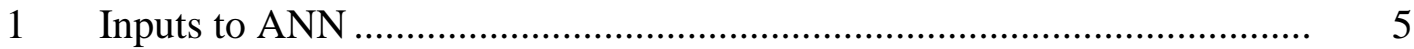

$2 \quad$ ANN description and properties..................................................... 32

$3 \quad$ Land-cover classes used in the study ................................................. 33

$4 \quad$ Landsat ETM+ training (1 through 11) and test (A, B and C) scenes....... 35

$5 \quad$ Total snow-covered area ............................................................. 45

$6 \quad$ RMSE and $\mathrm{R}^{2}$ for test scenes......................................................... 47

$7 \quad$ Snow-covered area per land cover .................................................. 56

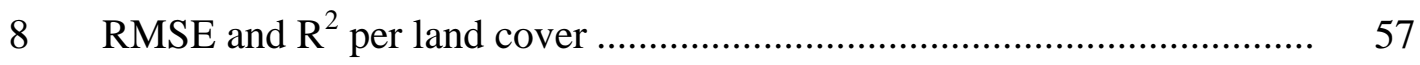

$9 \quad$ Number and percent training samples per land covers .......................... 62 


\section{INTRODUCTION}

\subsection{Importance of Snow-Cover Research}

Frozen precipitation in the form of snow accumulates during the winter season in mid- to high-latitude and mountain environments. This has important implications for the hydrology and climate of these geographic areas. As a frozen-water reservoir, snow holds the stored precipitation until snowmelt runoff is released into streams. Runoff from snowmelt can pose a hazard from flooding because it is often released rapidly during spring (Rango, 1996). However, snowmelt runoff is essential for the water supply of more than one-sixth of world's population who rely on fresh water from seasonal and glacial snowmelt (Barnett et al., 2005), including over 60 million people in the western United States (Bales et al., 2006).

Runoff predictions from snowmelt are acquired by including snow-cover parameters in hydrological models (Bales et al., 2006). Runoff from snow also supplies the necessary water for sustaining forest ecosystems in watersheds (Douville et al., 2002). In addition, snow plays a significant role in the fluvial geomorphology of higharctic watersheds as freshet carries sediments that are deposited in streams (Lamoureux et al., 2006). There is a recognized need to incorporate snow-cover extent and snowwater equivalent within hydrologic models to derive snowmelt-runoff estimates that provide more accurate forecasts of water supply, runoff rates and soil moisture recharge (Dozier, 1992). Thus, various snowmelt algorithms incorporate information about the

This thesis follows the style of Remote Sensing of Environment. 
evolution of snow-covered areas during the winter season (Liston, 1999).

Snow is also an important component of the climate system because of its characteristically high albedo in the visible and near-infrared ranges of the electromagnetic spectrum. It reflects most of the incoming solar radiation which in turn modifies the energy exchanges between the Earth's surface and the atmosphere over snow-covered areas causing these areas to experience lower temperatures than those without snowpack (Arnfield, 2006). Snow is also a poor conductor of heat, and snow cover acts as an insulator, not allowing the release of heat from Earth (Berry, 1981). Because snow cover affects energy exchanges at the surface, the areal extent of snow cover is incorporated in General Circulation Models (GCMs) (Marshall et al., 1994; Roesch et al., 2001) and forecasting models. However, a difficulty arises in modeling the snow's interactions with the atmosphere when inaccurate estimations of snow-cover extent exist within climate models (Niu \& Yang, 2007). For example, a warm bias over snow-covered regions in several of the National Center for Atmospheric Research Community Land Models has been attributed to inaccurate input of snow-cover extent (Dickinson et al., 2006).

The importance of accurate snow-cover-extent input into General Circulation Models (GCMs) is because of the positive feedback between snow cover and temperature (Randall et al., 1994). Higher global temperatures lead to larger snowmelt and less snowfall, which in turn decreases surface albedo while increasing absorption of solar radiation which further increases global temperatures. In this respect, ice and snowcovered surfaces have an essential cooling function for the whole planet (Prestrud, 
2007). If snow cover is underestimated in GCMs the output has a considerable warmtemperature bias. Conversely, overestimating snow-cover extent would cause predictions of colder temperatures than actual. Consequently, inaccurate climate-change models lead to erroneous climate-change conclusions which in turn may mislead decision makers and citizens. Thus, inadequate snow-cover estimates may have adverse social effects.

\subsection{Study Purpose and Objectives}

This study investigated the applicability of Artificial Neural Networks (ANNs) to successful mapping of snow fraction, which is the fraction of a remote-sensing pixel that is snow-covered. To accomplish this aim, a mutlilayer feed-forward ANN was trained with backpropagation and tested on Landsat Enhanced Thematic Mapper Plus (ETM+) scenes within North America representative of the different land covers typical of the snow-covered portions of the Northern Hemisphere. The methods is not intended to use in mountainous areas and therefore training and test scenes are selected over relatively flat areas.

Inputs to the network were the seven 500m MODIS land-surface reflectance bands provided in the Surface Reflectance Daily L2G Global 500m and 1km (MOD09GA) product (Vermonte \& Kotchenova, 2008), Normalized Difference Snow Index (NDSI) and Normalized Difference Vegetation Index (NDVI) which were calculated from the reflectance bands, and land cover in the International GeosphereBiosphere Programme (IGBP) classification scheme from the MODIS/Terra Land Cover 96 Day L3 Global 1 km ISIN Grid (MOD12Q1) product (Hodges, 2002) (Table 1). The reference snow fraction was determined by applying a binary snow-mapping algorithm 
(Hall et al., 1995) to higher resolution Landsat ETM+ images. The neural network was trained on eleven Landsat snow maps representative of different land covers and tested on three additional Landsat snow maps (Fig. 1). Finally, the snow-fraction maps produced through the ANN approach were compared to the snow-fraction maps provided as part of the MODIS/Terra Snow Cover Daily L3 Global 500m Grid (MOD10A1) product (Riggs et al., 2006).

ANNs have been applied in only a few snow studies. Simpson and McIntire (2001) use recurrent ANN to differentiate between cloud, land, snow and mixed snow and land pixels. The mixed pixels are then used in a spectral linear unmixing method to derive snow fraction. ANN have also been applied for deriving Snow Water Equivalent (SWE) and snow depth from Special Sensor Microwave Imager (SSM/I) brightness temperatures (Tedesco et al., 2004). 
Table 1

Inputs to ANN

\begin{tabular}{|c|c|}
\hline Input Feature & Description \\
\hline MOD09GA Band 1 & $\begin{array}{l}\text { Reflectance in the Red portion of the electromagnetic spectrum } \\
\qquad(620-670 \mathrm{~nm})\end{array}$ \\
\hline MOD09GA Band 2 & $\begin{array}{l}\text { Reflectance in the Near Infrared portion of the electromagnetic } \\
\text { spectrum(841-876 nm) }\end{array}$ \\
\hline MOD09GA Band 3 & $\begin{array}{l}\text { Reflectance in the Blue portion of the electromagnetic spectrum } \\
\qquad(459-479 \mathrm{~nm})\end{array}$ \\
\hline MOD09GA Band 4 & $\begin{array}{l}\text { Reflectance in the Green portion of the electromagnetic spectrum } \\
545-565 \mathrm{~nm} \text { (Green) }\end{array}$ \\
\hline MOD09GA Band 5 & $\begin{array}{l}\text { Reflectance in the Shortwave Infrared portion of the } \\
\text { electromagnetic spectrum }(1230-1250 \mathrm{~nm})\end{array}$ \\
\hline MOD09GA Band 6 & $\begin{array}{l}\text { Reflectance in the Shortwave Infrared portion of the } \\
\text { electromagnetic spectrum (1628-1652 nm) }\end{array}$ \\
\hline MOD09GA Band 7 & $\begin{array}{l}\text { Reflectance in the Shortwave Infrared portion of the } \\
\text { electromagnetic spectrum (2105-2155 nm) }\end{array}$ \\
\hline NDSI & $\begin{array}{l}\text { Normalized Difference Snow Index } \\
\text { (Band4 - Band6) }\end{array}$ \\
\hline & $\overline{(\text { Band } 4+\text { Band 6) }}$ \\
\hline NDVI & $\begin{array}{l}\text { Normalized Difference Vegetation Index } \\
\text { (Band2 - Band1) }\end{array}$ \\
\hline & $\overline{(\text { Band2 + Band 1) }}$ \\
\hline Land Cover (IGBP) & $\begin{array}{l}\text { Yearly land cover classification in the International Geosphere- } \\
\text { Biosphere Programme (IGBP) classification system }\end{array}$ \\
\hline
\end{tabular}




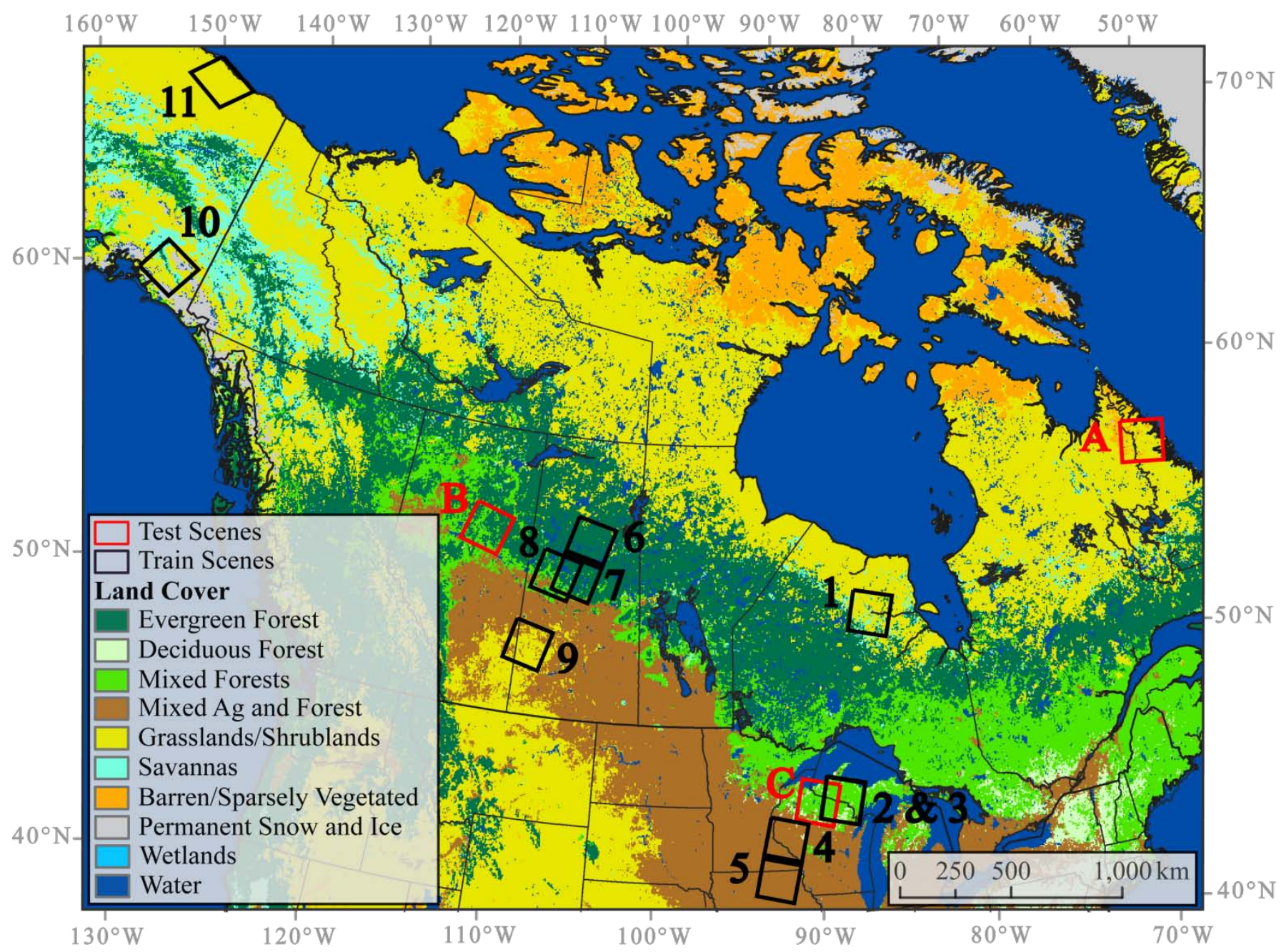

Fig. 1. Training and test Landsat scenes are located in North America. Training sites were selected to be representative of land covers. 


\section{LITERATURE REVIEW}

\subsection{Snow-Cover-Extent Mapping}

Snow-cover extent is one of the snow-cover characteristics that are included in both hydrologic and climate models (Rango, 1996; Roesch et al., 2001), and it is also monitored to supply information for climate-change studies (Lemke et al., 2007). One way of collecting snow-cover information is through in situ snow measurements from a snow course which involves manual collections of snowpack information along a transect (Derksen \& LeDrew, 2000). Another way of collecting field measurements of snow cover is through stationary snow-measuring instruments. Such instruments have been widely used by the United States Department of Agriculture since the 1970s and the archive of Snowpack Telemetry (SNOTEL) data has been applied to study snowcover properties and long-term changes in snowpacks (Serreze et al., 2001).

In situ methods, however, remain problematic for measuring snow-cover extent as the site where snow is sampled may not be representative of the entire study area, and the sampled site only gives snow-cover state at a particular location and does not provide information about whether the surrounding terrain is also snow-covered (Bales et al., 2006). Adverse weather conditions in snow-covered areas and the remoteness of these areas often make manual collection of consistent snow-cover information difficult or impossible (Derksen \& LeDrew, 2000). Further limitation of monitoring networks such as SNOTEL is the difficulty in accessing the instruments for maintenance. Stationary field instruments also require standardization of data collected from multiple sites and 
instruments, as well as corrections to account for wetting loss, wind-induced undercatch and trace snowfall events (Derksen \& LeDrew, 2000).

On the other hand, spaceborne and airborne remote sensing can be used instead or in addition to in situ snow-cover extent measurements. In fact, snow-cover maps produced by The National Oceanic and Atmospheric Administration/National Environmental Satellite, Data and Information Service are one of the longest environmental records produced using remote sensing (Robinson et al., 1993). The maps span a period of over four decades starting in 1966 and continuing to the present (NOAA 2009). Another example of the application of remotely-sensed images used for snowcover mapping is the maps produced automatically from MODIS images. These have been available since the launch of the Terra satellite in December 1999 (Hall et al., 2001). Using satellite remote sensing for monitoring of snow cover is advantageous because it offers consistent data collection over large geographical areas and thus longterm studies and environmental models have a continuous supply of measurements (König et al., 2001).

Snow-cover extent is easily observed in true-color images due to its high albedo in the visible wavelengths. Snow reflects close to $90 \%$ of the incoming solar radiation in the visible region of the electromagnetic spectrum. Thus, snow is easily distinguished from other Earth surface components (Hall et al., 2005). Snow also has a low albedo in the short-wave infrared range of the electromagnetic spectrum which allows for the construction of a normalized snow difference index (NSDI) (Dozier, 1989; Hall et al., 1995). This index is calculated by constructing a normalized ratio between reflectance in 
the green and reflectance in the shortwave infrared (SWIR) ranges of the electromagnetic spectrum:

$\mathrm{NDSI}=\frac{(0.6 \mu \mathrm{m}-1.6 \mu \mathrm{m})}{(0.6 \mu \mathrm{m}+1.6 \mu \mathrm{m})}$

The green range of the spectrum includes electromagnetic waves between $0.5 \mu \mathrm{m}$ and $0.6 \mu \mathrm{m}$ in length. The SWIR part of the spectrum includes waves with a length between $1.0 \mu \mathrm{m}$ and $3.0 \mu \mathrm{m}$. NDSI ranges from -1 to 1 with snow typically having NDSI of above 0.4 which highlights snow-covered areas. The index makes remote sensing in the optical part of the electromagnetic spectrum very effective for detection of snow cover and for mapping its extent (Hall et al., 2001).

However, despite the benefits of using remotely-sensed images for extracting snow-cover extent, clouds often obscure the surface in the optical wavelengths. Clouds, just like snow, have a high albedo in the visible range of the spectrum (Hall et al., 2005). The need for relatively cloud-free images imposes a limitation on the temporal resolution of the number of cloud-free observations. Temporal resolution refers to how frequently images over a specific area are collected. The length of time between observations is often referred to as the revisit period of a sensor. Depending on the application there may be a need for a very high temporal resolution. For example, snow mapping for meteorological forecasts requires current snow-cover information (Basist et al., 1996). At the same time, snow-cover extent may rapidly change as more snow accumulates or melts. Therefore, in order to create current snow-cover maps there is a need for daily or even twice daily revisit periods. 
While certain remotely-sensed images have a high temporal resolution they frequently have a very low spatial resolution. For example, Advanced Very High Resolution Radiometer (AVHRR) offers daily coverage, but has a spatial resolution of 1 $\mathrm{km}$ which means that each pixel within an AVHRR image covers an area of $1 \mathrm{~km}^{2}$. Moderate Resolution Imaging Spectroradiometer (MODIS) is another sensor that has daily revisit periods for most of the globe, but its spatial resolution is $500 \mathrm{~m}$, which means that a MODIS pixel covers an area of $0.25 \mathrm{~km}^{2}$. There is a tradeoff between spatial and temporal resolutions. At the same time, low spatial resolution means that a large area (for example, $0.25 \mathrm{~km}^{2}$ for a MODIS image) is approximated to being snowcovered or snow-free according to only $50 \%$ of its area. Such an approximation is problematic for hydrologic models (Bales et al., 2006; Dozier et al., 2008) and may also be related to inaccurate climate predictions (Niu and Yang, 2007).

\subsection{Fractional Snow Cover Mapping}

One way to address the limitations of low spatial resolution images is to construct snow-cover maps where snow cover in each pixel is represented as a percentage of the area covered by snow in the pixel. Since a pixel integrates the spectral information of the whole area viewed, the snowpack cannot be spatially located within the pixel. However, it is possible to estimate the percentage of snow in a pixel from the surface reflectance of the pixel recorded by the remote-sensing sensor. This is an improvement over traditional snow-cover maps that are binary and represent a pixel as either covered with snow or snow-free (König et al., 2001). Typically in binary snow maps, a pixel is classified as containing snow if approximately fifty percent of its area is 
snow-covered (Hall et al., 2002). This may introduce significant error in the estimations of the spatial extent of snow cover, which in return may cause erroneous results from hydrological (Rango, 1996) and General Circulation Models (GCMs) (Roesch et al., 2001). Even slight variations in Fractional Snow Cover (FSC) produce significantly different results in GCMs. Consequently, incorrect estimates of FSC result in biased climate predictions (Niu \& Yang, 2007).

\subsubsection{Linear Mixture Analysis}

A popular method for deriving subpixel estimates of surface abundance is linear mixture analysis, which is also known as linear spectral unmixing. A pixel contains the spectral information from all surface components within a sensor’s Instantaneous Field Of View (IFOV). Linear mixture analysis is performed with the assumption that the reflectance of a pixel is a linear combination of the surface components within that pixel and that the weight of each component equals the proportion of the pixel's IFOV that contains the component (Jensen, 2005). Endmembers are idealized, pure spectral signatures for a type of surface (Schowengerdt, 1997). The performance of the spectralunmixing model depends on availability of complete and accurate endmember sets which are usually stored in a spectral library referenced by the model during processing. Linear spectral unmixing had been applied extensively for deriving FSC. Nolin and Dozier (1993) reported a successful implementation of the method for mapping snow at subpixel level from images acquired with Airborne Visible/Infrared Imaging Spectrometer (AVIRIS) over the Sierra Nevada Mountain Range. For each image, endmember spectra were identified from pixels representative of specific surface 
components. The authors acknowledged that a component might in itself consist of several sub-elements, yet it might be represented by a single spectral signature. For example, a vegetation endmember was used as representative of all vegetation types. In that study endmember selection was performed manually, and later studies aimed at automating the linear mixture analysis for FSC mapping.

Simpson et al. (1998) described the Multi-spectral Multi-stage Snow Detection (MSSD) procedure which used iterative split-and-merge clustering combined with dynamic cluster labeling to discriminate between land, cloud and snow pixels and to identify mixed snow pixels. Spectral signatures of snow, cloud and land endmembers were the mean vectors of the reflectances of the appropriate clusters.

Further work included training Artificial Neural Networks (ANNs) to discriminate between snow, cloud and land pixels and identify mixed pixels (Simpson \& McIntire, 2001). The ANN returned three outputs each having a value of 0 or 1 pointing the absence or presence of the component in a pixel. Mixed land and snow pixels were thus indentified and passed to a linear spectral unmixing model which then determines the snow fraction in the mixed pixel. ANNs were recognized as especially useful in identifying mixed pixels because of their ability to extract relationships between input variables and to function well despite sensor noise and calibration uncertainties (Simpson \& McIntire, 2001). The approach was estimated to be successful in accurately delineating pure snow, cloud and land pixels. Its accuracy was related to the precision of the initial input to the ANN classifiers and to the number of training samples. 
A different approach to determining snow, land and cloud pixels and mixed snow pixels and to extracting reference endmembers' spectra was described by Shi (1999). The study automatically extracted endmember spectral signatures through a combination of image-based and in situ approaches. First, initial clustering of snow, snow-free and snow-mixed pixels through knowledge-based regression tree classifier was performed, and initial snow and snow-free endmembers were identified. Following that step was further classification of snow-mixed pixels through spectral-shape matching using the initially-identified endmembers. Then, snow and snow-free endmembers were merged to create mixed-snow endmembers, and the endmembers for the three classes were averaged to determine one spectral signature for each class. And finally, local vegetation and bare-surface endmember signatures were obtained by unmixing selected snow-free initial endmembers-candidates using in situ-collected spectral library of different snowfree components.

The above studies determined endmembers for each image, however, further work on linear spectral unmixing for snow-fraction mapping allowed per-pixel variation of endmembers (Painter et al., 2003; Painter et al., 2009). In the studies, each surface component was represented by a set of endmembers, snow endmembers differed depending on grain size. And each pixel was unmixed using permutations of two or more endmembers and the appropriate endmembers were selected according to a set of constraints. The calculated snow fraction through linear spectral unmixing was then shade normalized using calculated spectral fraction of photometric shade. Spectral libraries consisted of snow, soil, rock and vegetation endmembers, where snow 
endmembers of various grain sizes were derived from radiative transfer modeling, and the snow-free endmembers were collected in situ. At first, the best results were derived for areas lacking vegetation. The shading of snow by tree canopies was reported as a possible cause for the larger error over areas with dense vegetation (Painter et al., 2003). Later, canopy-level endmembers were included in the spectral library of the model to address the non-linear spectral mixing in forests (Painter et al., 2009).

A challenge in using satellite remotely-sensed images is clouds obscuring the surface and poor quality of observations. Dozier et al. (2008) used a time-series of daily MODIS snow fraction maps to fill the missing values. This was accomplished by first identifying the noise and cloud pixels. Then, smoothing and interpolation across time was applied to replace the missing values. Finally the space-time cube was smoothed with a Gaussian filter. Dozier et al. (2008) argued that daily snow-cover maps with filled values should be provided to users, as maps with gaps present were difficult to use in hydrologic models.

Since the performance of the linear unmixing model is related to the quality of endmembers’ spectral signatures, various studies used locally-collected in situ endmembers for developing FSC-mapping techniques for specific areas. Metsämäki et al. (2005) adjusted the linear spectral model for extracting FSC over Finland, and the model was used for hydrological modeling and for forecasting by the Finish Environmental Institute. Foppa et al. (2004) described their use of linear spectral unmixing over the European Alps and demonstrated the method's validation with ASTER data. Hongen and Suhong (2004) showed how a multiple endmember spectral- 
unmixing approach to processing AVHRR and MODIS data was utilized in determining FSC over the Tibetan Plateau. And Sirguey et al. (2009) used linear spectral unmixing to derive snow fraction over the Southern Alps of New Zealand. Unique in the study was that the 250m spatial resolution of MODIS bands 1 and 2 was utilized by producing snow maps at a $250 \mathrm{~m}$ resolution through image fusion. Aggregating to a $500 \mathrm{~m}$ resolution improved the accuracy of the FSC maps compared to the FSC maps where image fusion was not applied.

Snow shadowed by tree canopies poses a recurrent problem in snow-cover mapping through satellite imagery (Klein et al., 1998). Vikhamer and Solberg (2002, 2003) developed FSC methods targeted specifically at forested areas. Their sub-pixel reflectance (SnowFor) model used linear spectral unmixing and distinguished between bare, forested and snow-covered surfaces. The accuracy of the model was improved by accounting for the spectral reflectance from three of the most abundant tree species in the Norwegian Boreal Forest: birch, spruce and pine. The spectral characteristics of each of these species were collected in situ and stored in a spectral library. SnowFor was tested with Landsat TM data which had a much higher spatial resolution than the MODIS images used in SnowFor. Vikhamer and Solberg (2002, 2003) applied the method to derive the amount of snow cover from MODIS images; however, any type of remote-sensed images could be used with the model as long as the spatial footprint of the images is larger than the area covered by a tree (which is the case for most currently operating satellite systems). Using appropriate data, the SnowFor model could be used to map snow at subpixel resolution (SnowFrac). A study of how to apply these methods for 
mapping FSC from MODIS images introduced a constraint to the spectral mixture analysis. SnowFrac was applied to a mixed pixel only if it had a forest component. If no forest component was present in the mixed pixel its FSC was estimated without the SnowFrac model (Vikhamar \& Solberg, 2003).

The constrained linear spectral mixture analysis was tested on MODIS images between May 2000 and May 2001 over Southern Norway and was compared to snowcover maps derived from Landsat ETM+ images. The method estimated snow fraction remarkably well in forested areas. The success of the method was attributed to the large number of endmembers selected that were typical of the Norwegian Boreal Forest. Applying the method to a different area would require selection of endmembers representative of that specific area. In this respect, SnowFrac is considered a locationspecific model.

Another FSC method based on linear spectral unmixing was adopted in the production of automated snow maps by National Oceanic and Atmospheric Administration (Romanov et al., 2003). The method uses data acquired by Imager which is a sensor aboard the Geostationary Operational Environmental Satellite (GOES). An advantage of using data from a geostationary and not a polar-orbiting sensor was the geostationary sensors’ increased frequency of data acquisition. In this case data were acquired at least three times daily. The method was validated to perform well over areas with sparse or no vegetation such as cropland and other agricultural lands. Errors over vegetated areas were attributed to shadowing of the snow by tree canopies. The authors demonstrated that the relationship between FSC and tree cover fraction was nonlinear 
and therefore linear spectral unmixing was inadequate in representing the reflectance of a pixel containing both snow and forest components.

As illustrated by the FSC approaches developed by Vikhamer and Solberg (2002, 2003), modifications of linear spectral unmixing can account for the shadowing of snow in forests. Thus, an accurate estimation of the subpixel percentage of snow using linear spectral unmixing in forested areas is possible. However, the adjustment of each linear mixture model for a specific area requires the selection of endmembers representative of all surface components present in that area. This may be accomplished by collecting in situ endmembers from the areas where the spectral unmixing would be applied.

A problem with in situ-collected endmembers is relating them to the image.

Another problem is that if the spectral characteristics of the endmembers are measured in situ and stored in spectral libraries, these spectral libraries might not always be transferable to other areas because surface components may vary geographically. Varying topography in mountainous areas requires that endmember spectral signatures are collected from various slope and illumination conditions. Collection of extensive endmember libraries may be extremely time-consuming.

Snow reflectance is related mostly to grain size and impurities. The reflectance of the snow-free areas is related to type of land cover which is characterized by the specific components present in an area. For example, forests are typical of many snow-covered portions of the world; however, different locations have different combinations of tree species. Fine-tuning a linear spectral unmixing model to a specific area, requires that the model only uses surface components that are present in the area and that are contributing 
to the reflectance of each pixel. The need for location-specific selection of endmembers decreases the spatial extension of the technique.

\subsubsection{Empirical Approaches to Fractional Snow Cover Mapping}

Empirical studies to FSC-mapping built models based on examples of observed reflectance (predictor variables) and measured snow fraction (response variable). The predictor variables are the reflectance provided by remotely-sensed images and the response variable is estimated FSC through high resolution images or aerial photographs. Decision trees, a machine-learning technique, were trained to derive snow fraction from Landsat Thematic Mapper (TM) images (Rosenthal \& Dozier, 1996). The reference FSC for the training sample was created through linear mixture analysis of Landsat TM images, and the study suggested that the decision trees were only considered as part of an automated linear-mixture approach.

Kaufman et al. (2002), however, argued that a subpixel snow-fraction classifier applicable on a global scale has to rely only on the global spectral properties of the measured surface component. If such a method was applied, it would not need to be adapted for different geographic areas since it relied on characteristics of the measured surface component only. Previous research on remote sensing of aerosol particles in the atmosphere and the fact that both snow and aerosol appear to be dark at the $2.1 \mu \mathrm{m}$ and bright at the $0.66 \mu \mathrm{m}$ wavelength regions of the electromagnetic spectrum was utilized in the development of such a FSC method (Kaufman et al., 2002). The method operated by first establishing a relationship between the reflectance of snow-free pixels at the two wavelengths and then predicting what the reflectance in a snow-free pixel would be at 
$0.66 \mu \mathrm{m}$. Then, the algorithm examined each pixel and any extra reflectance at $0.66 \mu \mathrm{m}$ was attributed to snow and used to estimate the snow-cover fraction. The reflectance at $0.66 \mu \mathrm{m}$ was initially processed to correct for atmospheric effects. Since this FSC model relied on spectral properties, it was found to perform well on different spatial scales. Best performance was expected for pixels with less than 30 percent snow cover. Also, the method was only tested over the Sierra Nevada’s. Kaufman et al. (2002) suggested that the approach should be further validated or that similar approaches relying on global snow characteristics were developed.

Another FSC algorithm, which also relies on global spectral characteristics of snow, takes advantage of the difference in spectral reflectance of snow in the visible and shortwave infrared ranges of the electromagnetic spectrum. The method was developed for the Terra and Aqua MODIS instruments (Salomonson \& Appel 2004, 2006). A normalized difference snow index (NSDI) was constructed by using MODIS bands 4 and 6, which record reflectance in the green and short-wave infrared ranges of the spectrum, respectively. The statistical linear relationship of NDSI and snow fraction in a MODIS pixel was established empirically by using high-resolution Landsat snow maps as reference snow fraction. The method was estimated to be applicable globally and has been validated to perform more accurately than the FSC method developed by Kaufman et al. (2002). However, it was suggested that the accuracy of this approach was increased by adjusting it to specific geographic areas. Currently the model is used in for deriving FSC provided as part of the MODIS/Terra Snow Cover Daily L3 Global 500m Grid (MOD10A1) product (Riggs et al., 2006). 
Both the methods developed by Kauffman et al. (2002) and Salomonson and Appel $(2004,2006)$ rely on global spectral characteristics of snow and thus were applicable on a global scale. Neither approach, however, accounts for snow shadowed by tree canopies. As a result, the extent of snow cover in forested areas was underestimated. Underestimation of snow-cover extent in these areas could be attributing to the higher temperature bias in General Circulation Models (Dickinson et al., 2006; Niu \& Yang 2007) because possibly climate models predict more absorption of incoming solar radiation than is actually the case. A global- or even continental-scale FSC-mapping technique should be able to account for snow in forested areas especially if its results are used as inputs to environmental models.

The methods described by Salomonson and Appel (2004, 2006) and by Kaufman et al. (2002) overcome the limitation of linear spectral unmixing by not requiring endmembers and thus achieved large-scale applicability. At the same time these empirical approaches fall short of correctly estimating subpixel abundance of snow in all land covers due to their underestimation of snow in forests.

\subsection{Artificial Neural Networks Approach to Snow Fraction Mapping}

The limitations of the existing FSC approaches should be addressed to improve snow-fraction mapping. Several of the approaches have different classification accuracies in different land-cover types while other approaches focus on deriving FSC for particular land cover types only (Vikhamar \& Solberg 2002, 2003). All of the existing FSC approaches are linear while spectral mixing in forests is nonlinear. There is a need for implementing a nonlinear FSC approach that considers land cover. Artificial 
Neural Networks (ANNs) are one class of nonlinear technique that is capable of handling contextual information such as land-cover type.

ANNs are particularly useful for image processing because of their applications in pattern recognition (classification) and regression (function approximation). When applied to digital image processing, ANNs can be trained to recognize certain spectral patterns. The network stores the learnt patterns and it recovers them even when presented with only noisy or partial versions (Haykin 1999). The pattern-recognition capability of ANNs has been used in snow studies by Simpson and McIntire (2001) for deriving pure pixels of snow, land and cloud cover within a scene. These pixels were recognized by the ANN because it had learned the corresponding spectral pattern of each class.

Function approximation is another ANN capability that could be applicable to snow-fraction mapping but has not been described in the literature. Similar to the decision trees which were trained to estimate snow fraction (Rosenthal \& Dozier 1996), ANN learns relationship between predictor and response variables. Most commonly used for function approximation is backpropagation learning which is supervised. During backpropagation the network learns the relationship between the input and output variables by iteratively adjusting its parameters to minimize the error between the result at each of the iterations and the correct output. Given a sufficient number of training examples and a large number of training iterations, ANNs can successfully learn the relationship between snow-covered and snow-free areas based on the spectra of training examples. In snow studies, an ANN trained with backpropagation has previously been 
used to estimate snow water equivalent from remotely-sensed images (Tedesco et al., 2004).

\subsubsection{Advantages of Artificial Neural Networks}

There are several advantages of using ANNs for establishing complex relationships between variables. The first is that the network does not make any assumptions concerning the relationships between the variables. Thus, ANNs can handle both linear and nonlinear mixing of components (Guilfoyle et al., 2001). Such flexibility is advantageous for FSC modeling because in forested areas the mixing of snow-covered and snow-free surfaces has been demonstrated to be nonlinear (Romanov et al., 2003).

Second, unlike linear spectral unmixing, ANNs do not require spectral endmember information. Endmembers are problematic for several reasons. It is difficult to obtain the exact spectral reflectance of pure surface components in non-laboratory environments. Linear mixture analysis performs best when endmembers for all surface components present in a scene exist and are available. Also, endmembers can be difficult to determine, especially in vegetated areas (Filippi \& Jensen 2006). Thus, ANNs may be advantageous over linear mixture analysis in terms of ease of implementation.

\subsubsection{Artificial Neural Networks in Subpixel Studies}

There are various studies that utilize ANNs for determining the subpixel abundance of surface components. Foody et al. (1997) illustrated the method with a case study where AVHRR imagery of tropical forest was classified into pasture, forest and river land cover types. The study was one of the first attempts to use ANNs for subpixel classification in remote sensing. Foody et al. (1997) pointed that ANNs were preferable 
to linear spectral unmixing because they did not assume linear relationship between surface components in a pixel and they did not require collection of spectral endmembers.

Another study that presented a framework for utilizing ANN techniques for estimating subpixel abundance of surface components was presented by Lee and Lathrop (2006). The authors described a technique for estimating the subpixel percentage of impervious surface, grass and tree components within pixels of Landsat ETM+ imagery. The method was especially successful because it was able to distinguish between grassy and woody areas and, thus, presented a good representation of land cover types. There were other studies that also described ANN implementations for fractional land-cover estimation (Shabanov et al., 2005; Tatem et al., 2002).

\subsubsection{Artificial Neural Networks in Snow Studies}

ANNs had not only been used for determining subpixel abundance of surface components, but also for deriving certain snow-cover characteristics. In particular, Tedesco et al. (2004) used neural networks to extract snow-water equivalent and snow depth from images acquired by the Special Sensor Microwave Imager (SSM/I). Several training methods were employed, and it was estimated that the best performance was achieved when the network was trained with experimental data. This study is important because it presented an ANN method for deriving snow-cover characteristics from remotely-sensed images. ANN have also been used in avalanche hazard forecasting (Stephens et al., 2002) and in detecting and estimating snowfall using passive microwave images (Mejia et al. 2008). 


\section{METHODOLOGY}

\subsection{Artificial Neural Networks}

ANNs constitute an information-processing model that stores empirical knowledge and subsequently makes the stored knowledge available for future use. ANNs are loosely modeled after the brain of living organisms and resemble the brain in that knowledge is acquired from the environment through a learning process and is stored in the form of interneuron connection strengths (Haykin 1999).

\subsubsection{The Neuron}

The fundamental processing unit of ANNs is the neuron (Fig. 2). A neuron consists of connection links (synapses) characterized with certain weights (strength). Input is passed from one end of the synapse, multiplied by the connection weight and passed on to the summing junction (adder) of the neuron. The adder sums the weighted inputs:

$\mathrm{u}_{\mathrm{k}}=\sum_{\mathrm{j}=1}^{\mathrm{m}} \mathrm{w}_{\mathrm{kj}} \mathrm{x}_{\mathrm{j}}$

where $x_{j}$ represents the $j^{\text {th }}$ input signal from a total of $m$ inputs; $w_{k j}$ represents the strength of the connection weight from the $\mathrm{j}^{\mathrm{th}}$ input signal to neuron $\mathrm{k}$, and $\mathrm{u}_{\mathrm{k}}$ is the sum of the weighted input signals. 


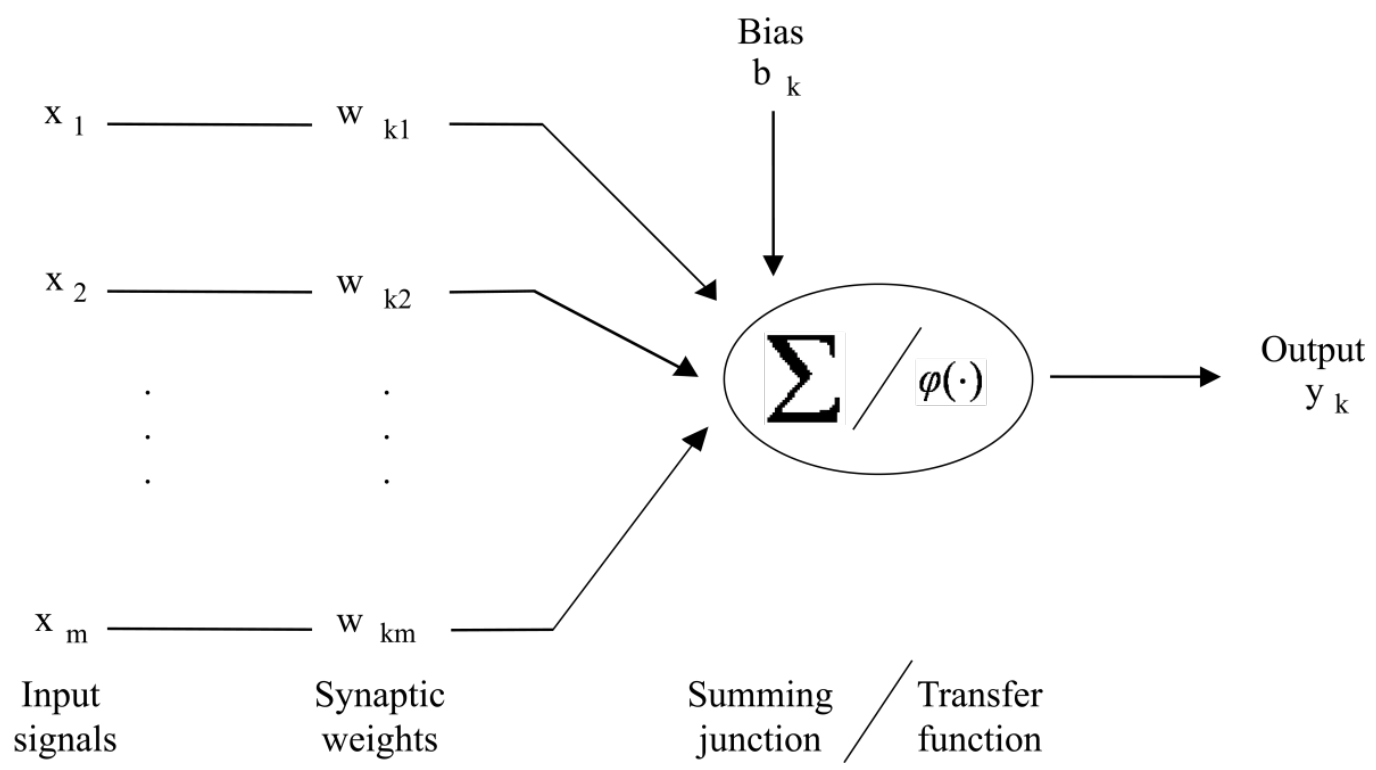

Fig. 2. Nonlinear model of a neuron. Adapted after Haykin (1999).

A bias $b_{k}$ is added to the linear combined output $u_{k}$ to derive the activation potential of $\mathrm{v}_{\mathrm{k}}$ of the neuron:

$\mathrm{v}_{\mathrm{k}}=\mathrm{u}_{\mathrm{k}}+\mathrm{b}_{\mathrm{k}}$

The activation potential $\mathrm{v}_{\mathrm{k}}$ is then passed to the transfer (activation or squashing) function $\varphi$, which computes the output $\mathrm{y}_{\mathrm{k}}$ of the neuron:

$\mathrm{y}_{\mathrm{k}}=\varphi\left(\mathrm{v}_{\mathrm{k}}\right)$

The two most common types of transfer functions are the threshold and sigmoid functions (Haykin 1999). The threshold function returns discrete output values depending on whether the activation potential of a neuron is below or above a predefined threshold. The sigmoid function, on the other hand, returns a range of continuous output values. It is also the most popular type of transfer functions (Haykin 1999). It has a typical S-shape curve and therefore it exhibits a balance between a linear and non-linear 
behavior. Furthermore, it is differentiable, which is a necessary in some types of supervised neural-network-learning methods such as backpropagation. Computing the derivative of the transfer function of a neuron is required in computing the error associated with the neuron.

The two common types of sigmoid transfer functions are the logistic sigmoid and tangent hyperbolic functions (Fig. 3). The logistic sigmoid returns output ranging between 0 and 1:

$\varphi\left(\mathrm{v}_{\mathrm{k}}\right)=\frac{1}{1+\mathrm{e}^{-\mathrm{v}_{\mathrm{k}}}}$

while the tangent hyperbolic returns output between -1 and 1 :

$\varphi\left(\mathrm{v}_{\mathrm{k}}\right)=\tanh \left(\mathrm{v}_{\mathrm{k}}\right)$

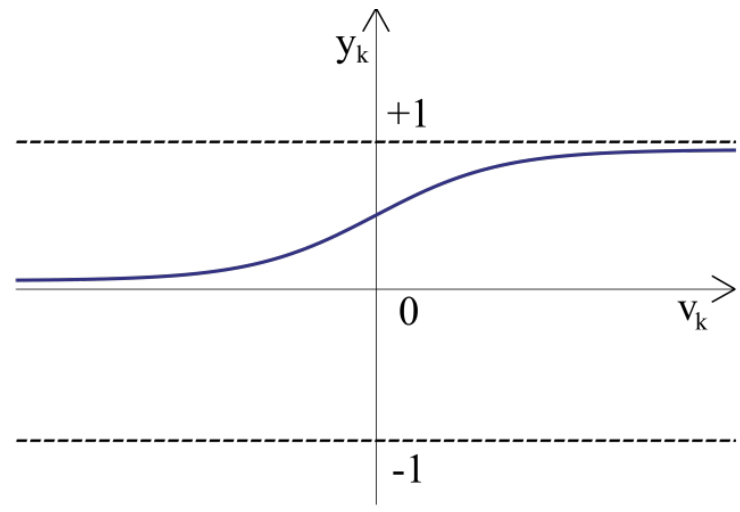

a) logistic sigmoid

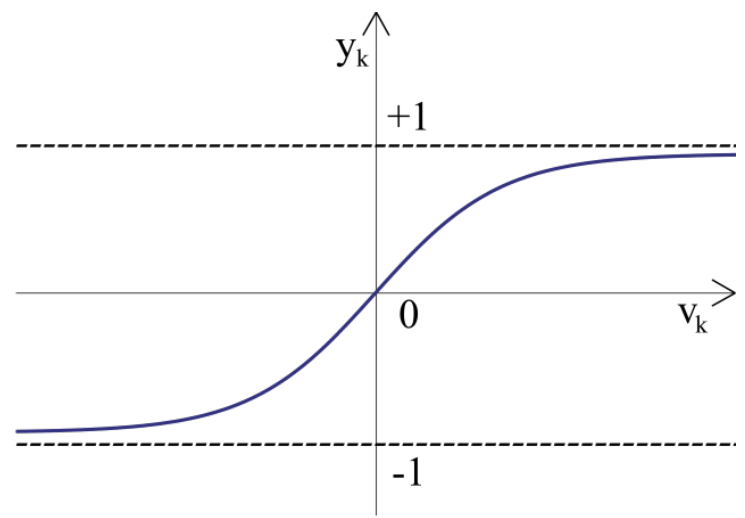

b) tangent hyperbolic

Fig. 3. Transfer functions. (a) Logistic sigmoid. (b) Tangent hyperbolic. 


\subsubsection{Artificial Neural Network Architecture}

Neurons are connected to each other through their connection links. Thus, the output of a neuron is transmitted through a connection link, multiplied by the weight of the connection link and passed to the summing junction of the next neuron. The way neurons are structured in an ANN is determined by the network’s architecture.

Typically, neurons are arranged in layers. Fig. 4 illustrates a multi-layer feedforward ANN architecture. The input layer does not consist of neurons, but of nodes which pass each input element to the first layer of neurons. In a remote sensing context an input layer is the available information about an image pixel such as reflectance, land cover or elevation. Each of the neurons in the first hidden layer receives weighted signal from the input layer and computes an output which is then passed to all of the neurons in the next hidden layer. The neurons in the final hidden layer pass their output to each of the neurons in the output layer. The output of each output layer neuron is returned as the output of the ANN. In the current application a multi-layer ANN with one hidden layer is used.

The ANN in Fig. 4 is feedforward, as opposed to recurrent, which means that the network does not have any feedback loops, i.e. inputs to a neuron are not influenced by the output of that neuron. The difference between single- and multi-layer networks is that in single layer ANNs the input layer of source neurons projects directly to the output layer, whereas in multi-layer ANNs one or more hidden layers between the input and output layers are present. 


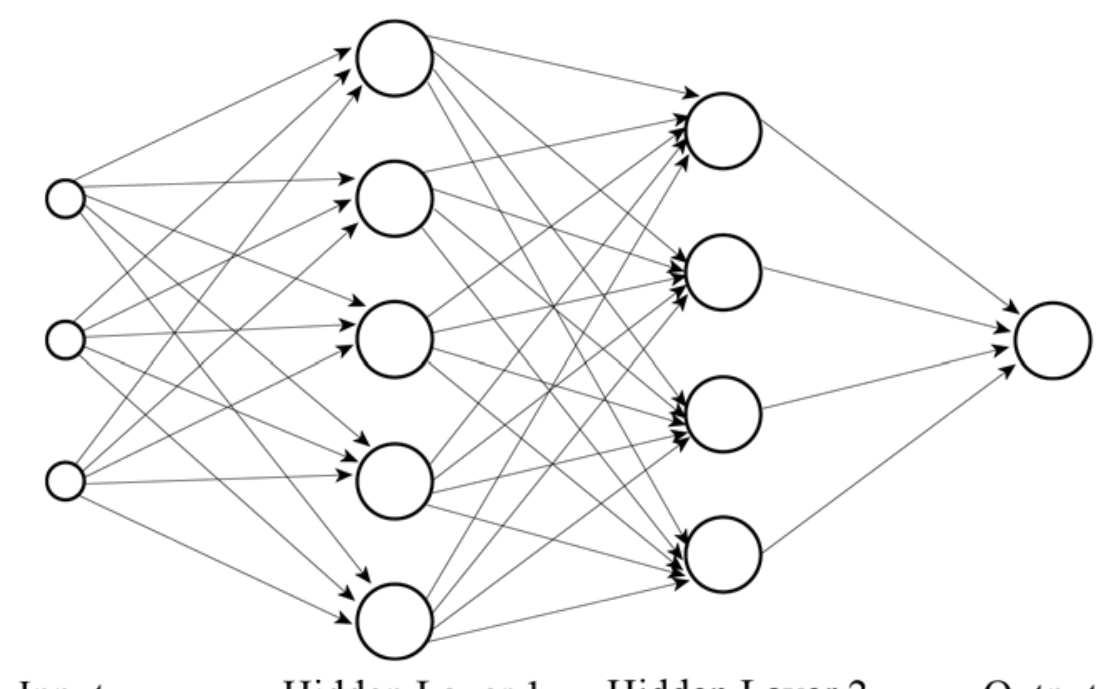

Input

Hidden Layer 1

Hidden Layer 2

Output

Fig. 4. A multi-layer feed-forward ANN.

\subsubsection{Learning}

ANNs learn a model of the environment so they can achieve the required goal of an application. Prior information could be built in the network or a network can acquire (learn) the knowledge from observations about (examples from) the environment through training. Examples could be labeled where each instance of the input signals is paired with a desired response (target output). In such case the learning process is categorized as supervised learning. When the examples are not labeled the process is called 'learning without a teacher' which could further be categorized as either unsupervised or reinforcement learning (Haykin 1999).

One of the most popular supervised learning methods is backpropagation which is a type of error-correction learning. The weights of the network are randomly 
initialized and the error signal is calculated as the difference between the generated and target outputs. The error is backpropagated and the weights are adjusted to minimize the error. The process is repeated iteratively until the error reaches a predefined minimal value or until the generalization performance of network starts to deteriorate based on a set of examples excluded from the training. Network generalization refers to how well an ANN performs on input that has not been used in training the network. The set of examples used for checking the generalization performance during training is called validation set.

Typically, after the training an ANN is tested with examples that have not been used either during training or validation. This stage of ANN implementation is called testing. If the results of the testing stage are unsatisfactory, the training processed is repeated. If an ANN is tested to perform well, its weights are stored for later use. When the model is used later for performing a task, it only references the saved weights.

\subsubsection{Properties of Artificial Neural Network in Current Study}

In this study, a multi-layer feed-forward ANN is trained with backpropagation to compute snow fraction. Nine inputs were provided to the network (Table 1). These include the seven MODIS surface reflectance bands provided in the Surface Reflectance Daily L2G Global 500m and 1km (MOD09GA) product (Vermonte \& Kotchenova, 2008). Calculated NDSI and NDVI were added to emphasize snow covered and vegetated areas, respectively. NDVI is a normalized difference ratio of bands in the red and near-infrared portions of the electromagnetic spectrum and is one of the vegetation indices used to indicate presence of healthy green vegetation (Jensen, 2005). 
Land-cover in the International Geosphere-Biosphere Programme (IGBP) classification scheme was also used as an input because spectral characteristics of snow are known to vary across land covers (Hall et al., 2001) and also because the reflectance of the snow-free surfaces depends on the surface type. The complete IGBP classification system was used as input to the ANN so that the network could learn to differentiate between different classes such as evergreen needleleaf forest and evergreen broadleaf forest.

Several input combinations were attempted before the final ten inputs were chosen. For example, the neural network was trained on the seven reflectance bands and land cover but without NDVI and NDSI. An additional input, percent tree fraction, was also considered but it was not included as its addition did not improve the results. The best input combination was determined based on Root Mean Square Error (RMSE) and $\mathrm{R}^{2}$ of the test samples which were selected from the training scenes.

The final neural network generated snow fraction values above 1 and below 0 . Such values are unrealistic as a pixel cannot have a negative amount of snow cover and cannot have snow cover exceeding 100 percent of the pixel. Therefore, FSC values larger than 1 were set to 1 , and smaller than 0 were set to 0 .

The following network properties were determined by trial-and-error: number of hidden-layer neurons, input-to-hidden transfer function and input-output normalization method. The neural network was trained while holding initial weights constant during the different runs to ensure that differences of the results were not caused by differences in initializations. Performance of the network was analyzed in terms of RMSE and by 
visually comparing resulting ANN FSC maps to reference FSC maps. ANN properties are summarized in Table 2.

One hidden layer was chosen as it had been demonstrated that a single hidden layer can learn any mapping (Priddy \& Keller, 2005). The number of hidden-layer neurons was chosen to be 20 which was twice the number of inputs. Experimenting with 10 and 30 hidden-layer neurons was attempted and the ANN performance in terms of RMSE was best with 20 neurons.

The nonlinear transfer function was also determined by trial-and-error. A tangent hyperbolic transfer function between the input and hidden layer was selected for the final network but a logistic sigmoid transfer function was also tested. These are the two most common sigmoid transfer functions. The two approaches were tested with different input and output normalization methods as input features are often normalized to the same range to minimize bias of the network towards any of the inputs (Priddy \& Keller, 2005). An input feature refers to all of the observations of a single input element across all examples. For example, an input feature is the set of all values of a band for all samples in the training, validation and test data sets. If a normalization method is used, the reverse normalization is applied to the target output and the normalized target output is used during training. After training, all generated output is also reverse-normalized to convert to physically-meaningful output. 
Table 2

ANN description and properties

\begin{tabular}{|l|l|}
\hline ANN Property & Description \\
\hline Training method & Levenberg-Marquardt backpropagation (supervised) \\
\hline Learning method & $\begin{array}{l}\text { Gradient descent with momentum weight and bias learning } \\
\text { function }\end{array}$ \\
\hline Performance measure & Mean Square Error (MSE) \\
\hline Network architecture & $\begin{array}{l}\text { Nine input neurons, one hidden layer with 20 hidden layer } \\
\text { neurons, and one output neuron }\end{array}$ \\
\hline Transfer functions & $\begin{array}{l}\text { Tangent hyperbolic between input and hidden layers; } \\
\text { Linear between hidden and output layers }\end{array}$ \\
\hline $\begin{array}{l}\text { Input/output } \\
\text { normalization }\end{array}$ & Each input band is scaled between -1 and 1 \\
\hline
\end{tabular}

\subsection{Reference Fractional Snow Cover Maps}

The performance of ANNs trained in a supervised manner is closely related to the quality of the data set used for training (Priddy \& Keller, 2005), and therefore a training data set should be representative of the pixels that it would be used on. In the current study, it was important that the training examples were not biased towards a certain land-cover but instead adequately represented the land covers typical of mid- and high-latitude snow-covered environments. The training set should also not be biased towards particular snow cover fractions. Therefore stratified random sampling across land cover and snow fraction was performed to create the training, validation and test data sets. 


\subsubsection{Landsat ETM+ Scene Selection and Preprocessing}

Selection of training and test scenes was restricted to partially snow-covered images acquired within North America during different months of the snow season. The main objective in selecting the training scenes was to represent land covers typical of the snow-covered mid to high latitudes. The land-cover classification system used in selecting samples combined the seventeen IGBP land-cover classes into eight: evergreen forest, deciduous forest, mixed forest, mixed agriculture, barren/sparsely vegetated, savannas, grasslands/shrublands and wetlands (Table 3) as a similar approach was used previously by Hall et al. (2001) to assess the accuracy of the MODIS snow product.

\section{Table 3}

Land-cover classes used in the study

\begin{tabular}{|c|c|}
\hline $\begin{array}{l}\text { IGBP Land-cover Classes } \\
\text { (used as input) }\end{array}$ & Reclassified For Sampling \\
\hline Evergreen needleleaf forest & \multirow{2}{*}{ Evergreen forests } \\
\hline Evergreen broadleaf forest & \\
\hline Deciduous needleleaf forest & \multirow{2}{*}{ Deciduous forests } \\
\hline Deciduous broadleaf forest & \\
\hline Mixed forests & Mixed forests \\
\hline Croplands & \multirow{3}{*}{ Mixed agriculture } \\
\hline Urban and built-up & \\
\hline Cropland/natural vegetation mosaic & \\
\hline Barren/sparsely vegetated & Barren/sparsely vegetated \\
\hline Woody savannas & \multirow{2}{*}{ Savannas } \\
\hline Savannas & \\
\hline Closed shrublands & \multirow{3}{*}{ Grasslands/shrublands } \\
\hline Open shrublands & \\
\hline Grasslands & \\
\hline Permanent wetlands & Wetlands \\
\hline Permanent snow and ice & $\mathrm{n} / \mathrm{a}$ \\
\hline Water & $\mathrm{n} / \mathrm{a}$ \\
\hline
\end{tabular}


The Landsat ETM+ scenes which were used for selecting training examples (Table 4) were selected for minimal cloud cover and were acquired between 2000 when MODIS became operational and 2003 when the Landsat ETM+ Scan Line Corrector (SLC) failed which degraded image quality (NASA, 2009b). Three of the selected scenes were previously used in developing the NDSI snow fraction method for mapping FSC (Salomonson \& Appel, 2004, 2006).

Landsat ETM+ images were obtained free of charge from the United States Geological Survey (USGS) Earth Resources Observation and Science (EROS) data center. This product is corrected from distortions related to sensor, satellite and Earth effects. All scenes were georegistered to a Universal Transverse Mercator (UTM) projection with a WGS84 datum. Each of the Landsat ETM+ images was converted to radiance using a standard approach (NASA, 2009b). Atmospheric correction and conversion to radiance was then performed using the Fast Line-of-sight Atmospheric Analysis of Spectral Hypercubes (FLAASH) module in the ENVI 4.5 software package (Kaufmann et al., 1997). For three of the scenes (Table 4) FLAASH was unsuccessful and therefore a simpler modified black body correction (Chavez, 1988) was applied. Finally, the atmospherically-corrected scenes were compared to orthorectified Landsat ETM+ images which were acquired through the Global Land-cover Facility (GLCF, 2009). Most of the scenes (Table 4) had to be georegistered through selection of Ground Control Points (GCPs) because of geolocation differences between the orthorectified scenes and those used in the study. At least fifteen GCPs were selected for each scene with a Root Mean Square (RMS) error of less than 0.1 pixels. 
Table 4

Landsat ETM+ training (1 through 11) and test (A, B and C) scenes

\begin{tabular}{|c|c|c|c|c|}
\hline Scene & $\begin{array}{l}\text { WRS-2 } \\
\text { Path/Row }\end{array}$ & $\begin{array}{l}\text { Date } \\
\text { Acquired }\end{array}$ & Land-covers & $\begin{array}{l}\text { Number of } \\
\text { Samples }\end{array}$ \\
\hline \multicolumn{5}{|c|}{ Training Scenes } \\
\hline $1^{1,2}$ & $24 / 23$ & $04 / 24 / 2000$ & $\begin{array}{l}\text { Savannas, } \\
\text { grasslands/shrublands, } \\
\text { wetlands }\end{array}$ & 4,400 \\
\hline 2 & $24 / 28$ & 12/10/2002 & $\begin{array}{l}\text { Deciduous forests, mixed } \\
\text { forests, mixed agriculture }\end{array}$ & 6,209 \\
\hline 3 & $24 / 28$ & 02/28/2003 & $\begin{array}{l}\text { Deciduous forests, mixed } \\
\text { forests }\end{array}$ & 1,853 \\
\hline 4 & $26 / 29$ & 02/07/2002 & $\begin{array}{l}\text { Deciduous forests, mixed } \\
\text { forests, mixed agriculture }\end{array}$ & 2,446 \\
\hline 5 & $26 / 30$ & 02/07/2002 & Mixed agriculture & 1,288 \\
\hline 6 & $38 / 21$ & $12 / 25 / 2001$ & Evergreen forests & 1,400 \\
\hline 7 & $38 / 22$ & 03/19/2003 & $\begin{array}{l}\text { Evergreen forests, mixed } \\
\text { forests, savannas }\end{array}$ & 2,228 \\
\hline 8 & $39 / 22$ & 11/01/2002 & $\begin{array}{l}\text { Evergreen forests, mixed } \\
\text { forests, mixed agriculture, } \\
\text { savannas }\end{array}$ & 4,625 \\
\hline 9 & $39 / 24$ & 11/01/2002 & $\begin{array}{l}\text { Mixed agriculture, } \\
\text { grasslands/shrublands }\end{array}$ & 2,000 \\
\hline $10^{1,2,3}$ & $65 / 17$ & 05/12/2001 & $\begin{array}{l}\text { Savannas, } \\
\text { grasslands/shrublands }\end{array}$ & 3,400 \\
\hline $11^{1,2,3}$ & $73 / 11$ & 05/23/2002 & $\begin{array}{l}\text { Barren/sparsely vegetated, } \\
\text { grasslands/shrublands }\end{array}$ & 1,800 \\
\hline \multicolumn{5}{|c|}{ Test Scenes } \\
\hline$A^{2,3}$ & $11 / 20$ & 11/07/2000 & $\begin{array}{l}\text { Barren/sparsely vegetated, } \\
\text { grasslands/shrublands }\end{array}$ & 61,531 \\
\hline B & $43 / 21$ & 04/19/2002 & $\begin{array}{l}\text { Evergreen forests, mixed } \\
\text { forests }\end{array}$ & 116,874 \\
\hline $\mathrm{C}$ & $25 / 28$ & 04/08/2003 & $\begin{array}{l}\text { Deciduous forests, mixed } \\
\text { forests, mixed agriculture }\end{array}$ & 96,282 \\
\hline \multicolumn{5}{|c|}{$\begin{array}{l}{ }^{1} \text { Modified Black Body Atmospheric correction used instead of FLAASH. } \\
2 \text { Additional georeferencing was not performed } \\
{ }^{3} \text { Scene used in developing MODIS FSC product (Salomonson and Appel 2004, } \\
\text { 2006) }\end{array}$} \\
\hline
\end{tabular}




\subsubsection{Landsat Snow Maps}

Each of the pre-processed Landsat ETM+ images was used as input to a snowcover mapping algorithm (Hall et al., 1995) which classified pixels as either snowcovered or snow-free. This is the algorimth used for creating the standard MODIS binary snow-cover product (MOD10). The 30-m Landsat snow maps were then used to calculate snow fraction within each MODIS pixel. The land surface reflectance bands provided in MOD09GA have a 500 m spatial resolution. However, MODIS geolocation errors (Wolfe, 2006) mean that each pixel samples a slightly larger area. A common approach for dealing with the geolocation differences is to calculate the snow fraction within a larger spatial footprint than the extent of a pixel. For example, in the validation of the snow-fraction method described by Painter et al. (2009) sampling was performed within a circular footprint with radius ranging from $500 \mathrm{~m}$ to $2000 \mathrm{~m}$. In this study, a more conservative 750 m radius was applied (Fig. 5). 


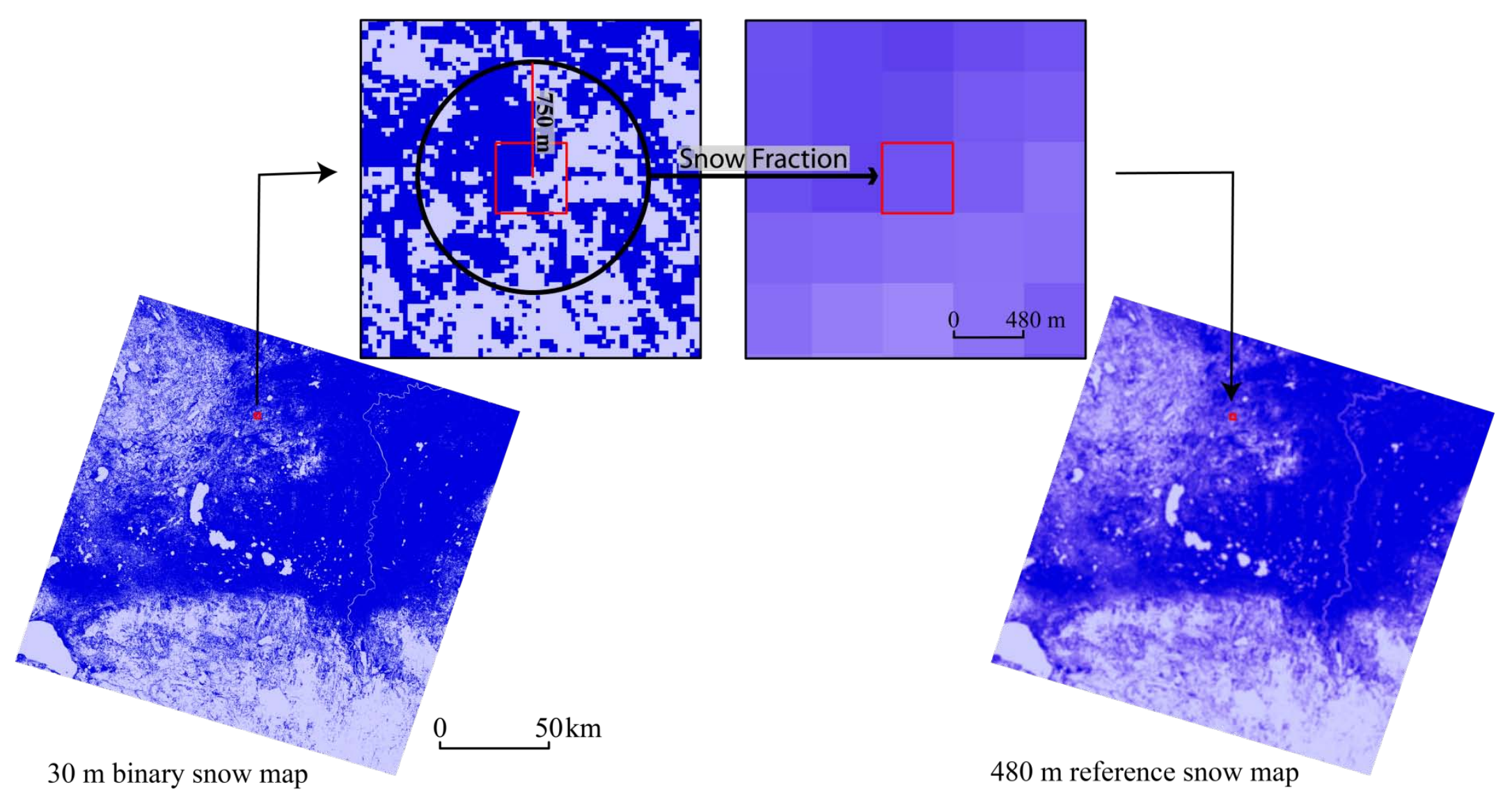

Fig. 5. Resampling to MODIS resolution. Binary snow-cover maps were resampled to MODIS resolution within a 750-m circular radius around each MODIS pixel. 


\subsection{MODIS Preprocessing}

MODIS is an instrument aboard the Terra and Aqua satellites which carry remote-sensing sensors designed for global environmental monitoring. MODIS aquires images from every point on Earth at least once every 1 or 2 days in 36 discrete spectral bands (NASA, 2009c). Science teams have developed a variety of standard data products which are distributed free of charge. The MODIS Surface Reflectance provides surface spectral reflectance in seven bands (Table 1) and is corrected for atmospheric effects (Vermonte \& Kotchenova, 2008). The product is distributed by the Land Processes Distributed Active Archive Center (NASA, 2009a). Seven land surface reflectance bands at $500 \mathrm{~m}$ and $250 \mathrm{~m}$ spatial resolution are provided in the Surface Reflectance Daily L2G Global 500m and 1km (MOD09GA) product and the product was used in the study. The product also contains data sets describing cloud cover and data quality for each pixel.

The data sets in the MOD09GA product are provided in the MODIS sinusoidal projection and in the current study were re-projected to a UTM projection with a WGS84 datum to match the respective reference snow maps. The reflectance data sets were also scaled by 0.0001 to convert from radiance to reflectance.

Water was excluded from the analysis using the water mask acquired from the MODIS land-cover product MOD12Q1. The cloud state and quality data sets provided with the MOD09GA product were analyzed to exclude pixels that were cloud-covered, mixed, fell within cloud shadow or had been produced at less than ideal quality from further analysis. Finally, areas identified by visual examination as cloud covered in the Landsat images were also masked. 


\subsection{Sampling}

A total of eleven Landsat snow maps (Fig. 1) were sampled to create the training, validation and test data sets. Following usage in the ANNs literature both the training and validation data sets were used during network training. The samples from the training data set were used in adjusting the weights of the ANN. The validation data set was used to measure the generalization performance of the network as represented by the mean square error (MSE) between the ANN FSC output and reference FSC output. Training ended when MSE of the validation set began to increase indicating that further training would decrease the generalization abilities of the network (Haykin, 1999).

To minimize training bias towards any land cover or snow-cover fraction, sample points were selected through stratified random sampling. Snow-cover fraction was categorized in 0.1 FSC intervals. Fig. 6 illustrates how random points were selected for the evergreen land cover class from training scene eight (Table 4). Due to scene availability some land covers were underrepresented in some FSC classes (Fig. 7). 


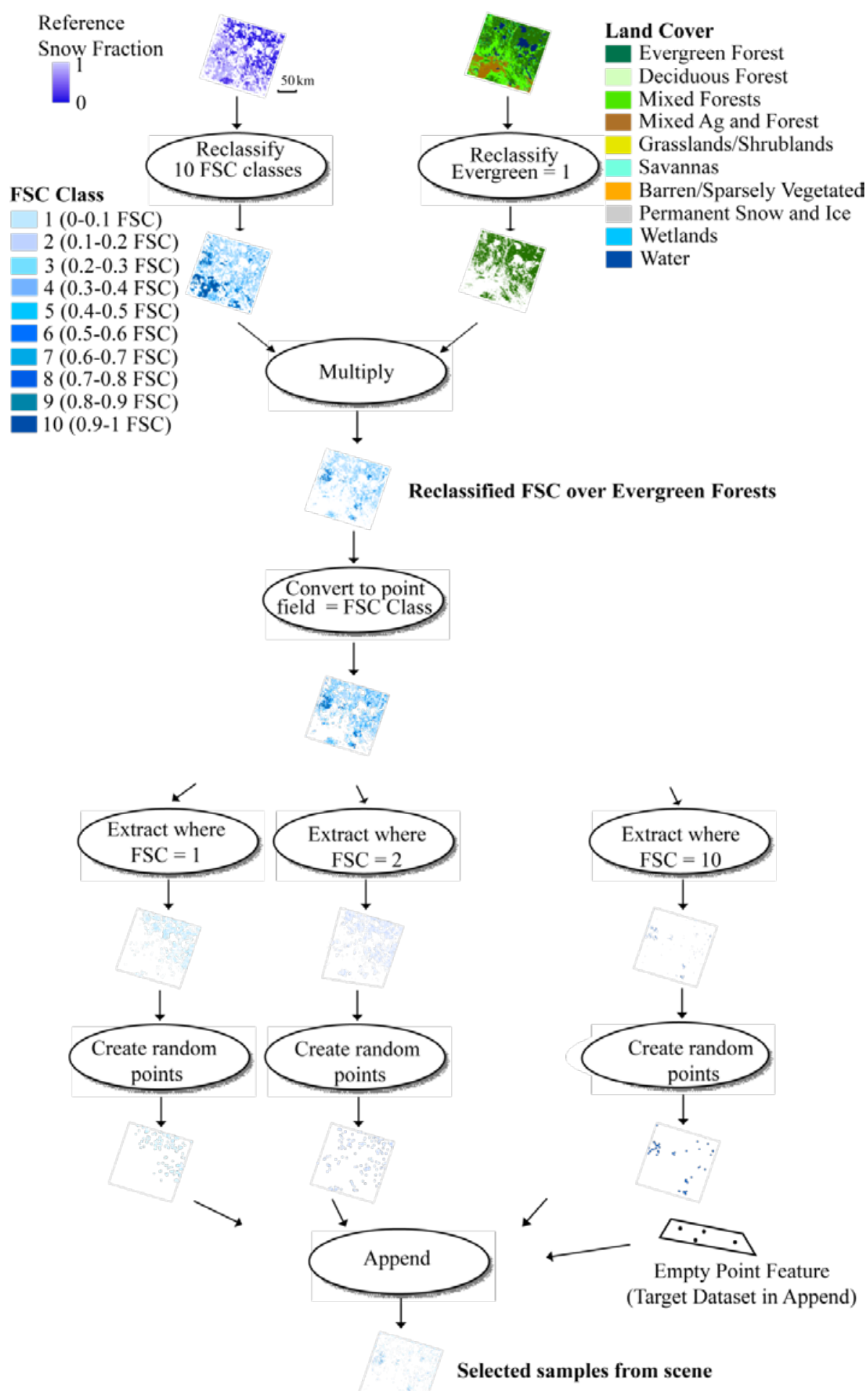

Fig. 6. Stratified random sampling per land cover and snow fraction. The figure illustrates selection of random points over evergreen forests for training scene eight. 


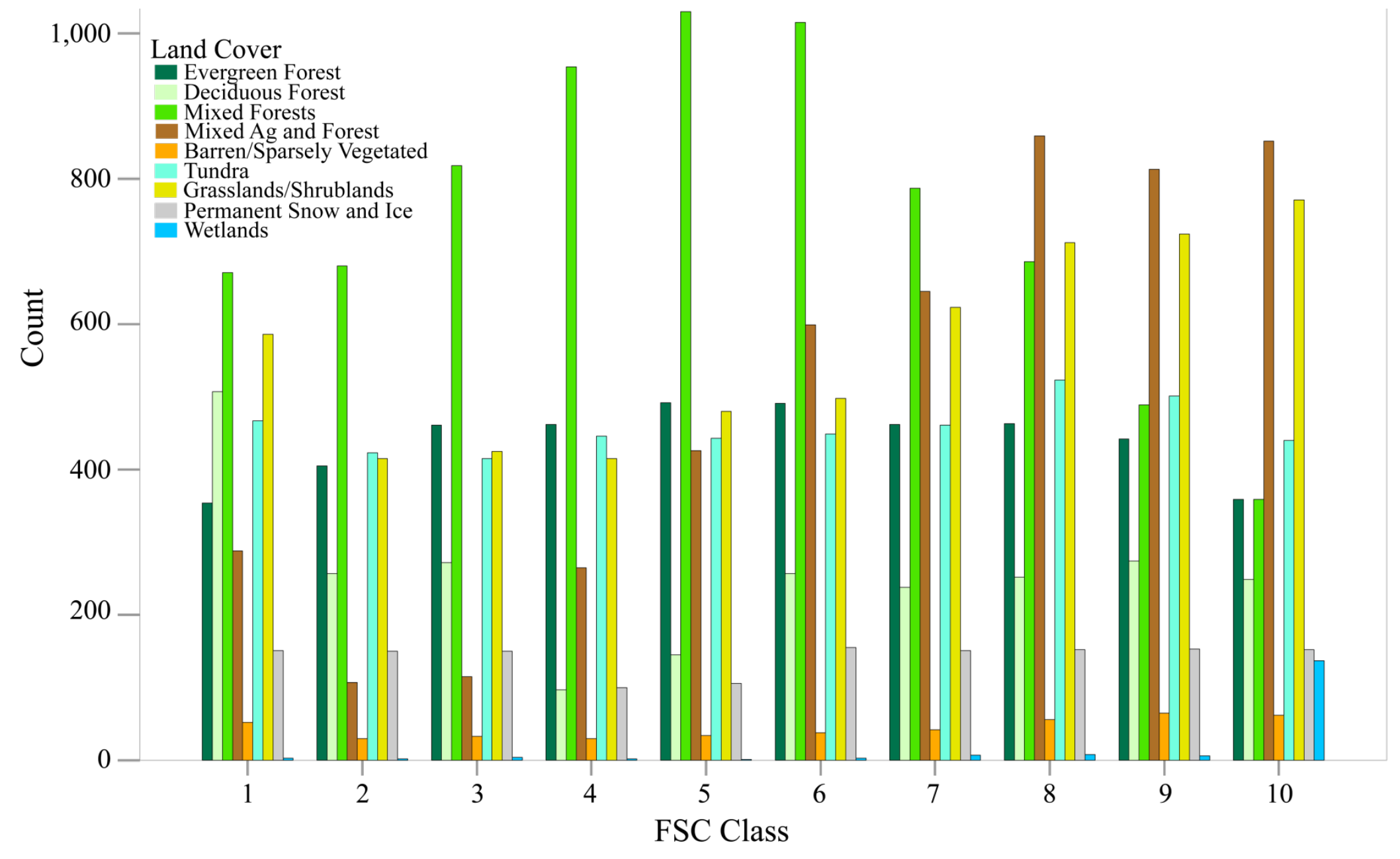

Fig. 7. Sample points used in final ANN. 


\subsubsection{Refinement of Samples and Network Training}

After sampling, the eleven Landsat ETM+ images used for creating the reference snow maps were visually examined. It was determined that some clouds had not been detected before sample point selection. Therefore, 297 points were removed from the sample data set because of apparent contamination by cloud cover or shadows. The final sample data set included 31,649 observations (Fig. 7). It was subsequently split in three fractions. One half of the samples were used for training, a fourth of the samples for network validation and the remaining was retained for testing the trained network.

After determining the ANN architecture, the sample data set which included the pixels randomly sampled from the eleven Landsat training scenes was examined. Approximately 200 samples had errors of computed FSC larger than three standard deviations of the mean and were removed. The network was trained on the remaining data set. Different runs were performed allowing for random initialization of weights. The ANN initialized with the saved initial weights had best performance and its results were further analyzed by examining scatter plots comparing the neural network generated FSC and reference FSC for each of the Landsat reference training scenes. The estimated FSC of the samples from training scene 3 (Table 4) was considerably underestimated. Samples from this scene were removed and a final ANN was trained using the saved initial weights.

Three additional Landsat snow maps (Fig. 1) were selected and reserved to independently test the results on scenes not used during training. Test Scene A (Table 4) was located in Labrador, Canada and contained barren/sparsely vegetated and 
grassland/shrublands land covers. Test Scene B contained evergreen and mixed forests and was located in Alberta, Canada. And Test Scene C contained deciduous and mixed forests and mixed agriculture. It was located in Michigan and Wisconsin, United States. All of the available MODIS pixels in these scenes were used in testing the trained network.

\subsection{Application Software Used in the Study}

Landsat and MODIS preprocessing was performed in ENVI 4.5 and IDL 7.0.

Selection of random points was performed in ArcGIS 9.3. Feed-forward ANN

implementation in the MATLAB R2008b Neural Network Toolbox was used. Statistical analysis was performed in SPSS 17.0. 


\section{RESULTS}

The performance of the ANN was analyzed by examining FSC maps for three reference Landsat snow maps which were not used to train the network. The test snow maps were prepared similarly to the ones used for creating the training, test and validation data sets. Test scene A covered a portion of Labrador, Canada and was acquired on November $7^{\text {th }}$, 2000 and has mostly barren/sparsely vegetated and grasslands/shrublands land-covers. This scene was also used in the development of the MODIS snow fraction algorithm (Salomonson \& Appel, 2004, 2006). Test scene B was acquired over Alberta, Canada on April 19 ${ }^{\text {th }}, 2002$ and is representative of evergreen forests and mixed forests. Test scene C was acquired over Michigan on April 8th, 2003 and it contains mostly deciduous forests, mixed forests and mixed agriculture land covers.

\subsection{Overall Mapping Accuracy}

The overall mapping accuracy of the ANN-derived snow fraction maps was good as the total snow-covered area mapped in the test scenes was similar to the total snowcovered area in the reference snow-fraction maps (Table 5; Figs. 8, 9). Specifically, the ANN FSC estimated a combined total of $35,152 \mathrm{~km}^{2}$ snow-covered are for the three test scenes which is $56 \%$ of the total area while the reference snow-cover extent was 37,531 $\mathrm{km}^{2}$ which is $59 \%$ of the total area. The neural network underestimated the snow-cover extent by $2379 \mathrm{~km}^{2}$ or $3 \%$ of the total area. This means that for each $100 \mathrm{~km}^{2}$ in the reference FSC map that ANN mapped $3 \mathrm{~km}^{2}$ less snow. The best performance was over test scene B for which ANN underestimated the snow cover by $1 \mathrm{~km}^{2}$ per $100 \mathrm{~km}^{2}$. The 
snow cover was underestimated by $5 \mathrm{~km}^{2}$ per $100 \mathrm{~km}^{2}$ and $6 \mathrm{~km}^{2}$ per $100 \mathrm{~km}^{2}$ for test scenes $\mathrm{C}$ and $\mathrm{A}$, respectively.

\section{Table 5}

Total snow-covered area. Snow-cover extent in square kilometers and as percentage of the area of the three test scenes individually and combined.

\begin{tabular}{|c|c|c|c|c|c|}
\hline & & \multicolumn{4}{|c|}{$\begin{array}{c}\text { Snow-Covered Area } \\
\left(\mathbf{k m}^{2}\right) /(\text { percent of total area) }\end{array}$} \\
\hline $\begin{array}{c}\text { Test } \\
\text { Scene }\end{array}$ & $\begin{array}{c}\text { Total } \\
\text { area } \\
\left.\mathbf{k m}^{2}\right)\end{array}$ & Reference & ANN & $\begin{array}{c}\text { MOD10 } \\
\text { (snow } \\
\text { fraction) }\end{array}$ & $\begin{array}{c}\text { MOD10 } \\
\text { (binary) }\end{array}$ \\
\hline A & 14,177 & $12,299 / 87$ & $11,671 / 82$ & $12,451 / 88$ & $12,760 / 90$ \\
\hline B & 26,928 & $9,222 / 34$ & $8,950 / 33$ & $8,166 / 30$ & $12,525 / 47$ \\
\hline C & 22,183 & $16,010 / 72$ & $14,531 / 66$ & $14,794 / 67$ & $18,076 / 82$ \\
\hline All & 63,288 & $37,531 / 59$ & $35,152 / 56$ & $35,411 / 56$ & $43,361 / 69$ \\
\hline
\end{tabular}
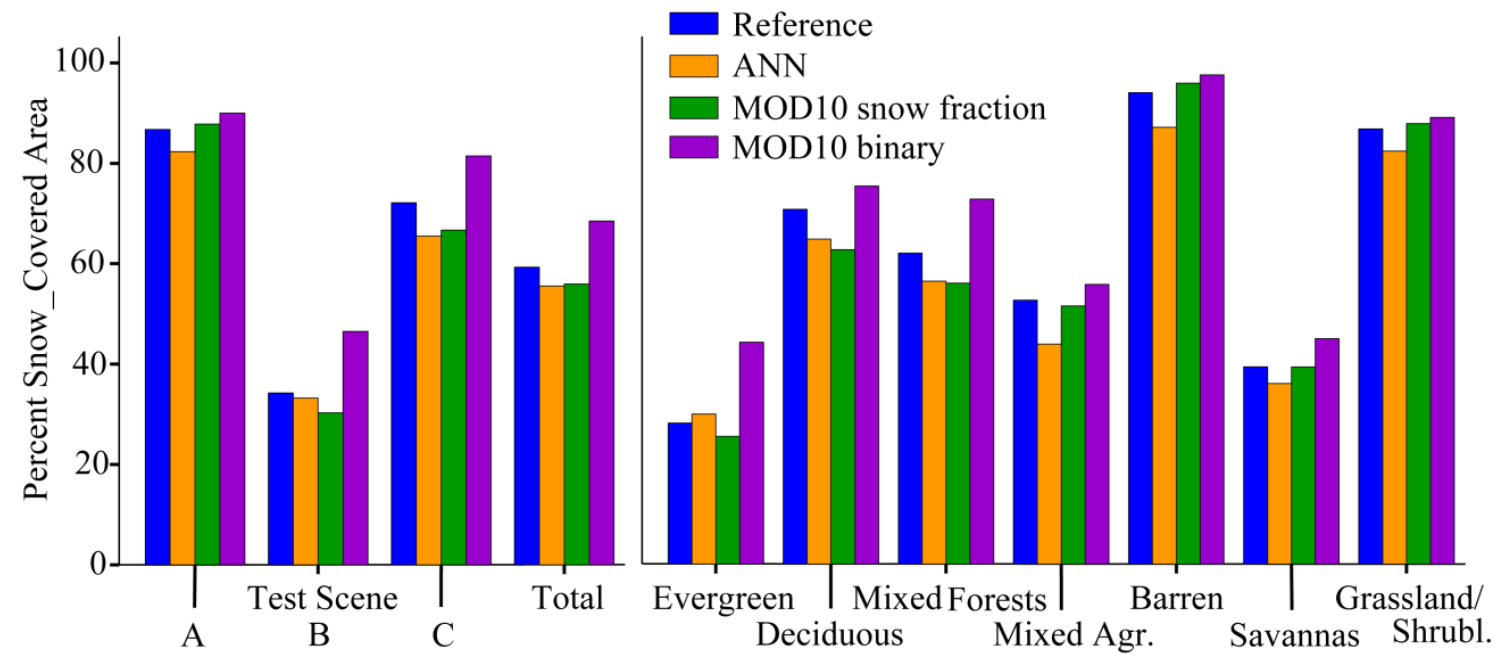

Fig. 8. Total snow-covered area. Snow-cover extent as percentage of the total area for the three test scenes and combined and for the different land-covers. 


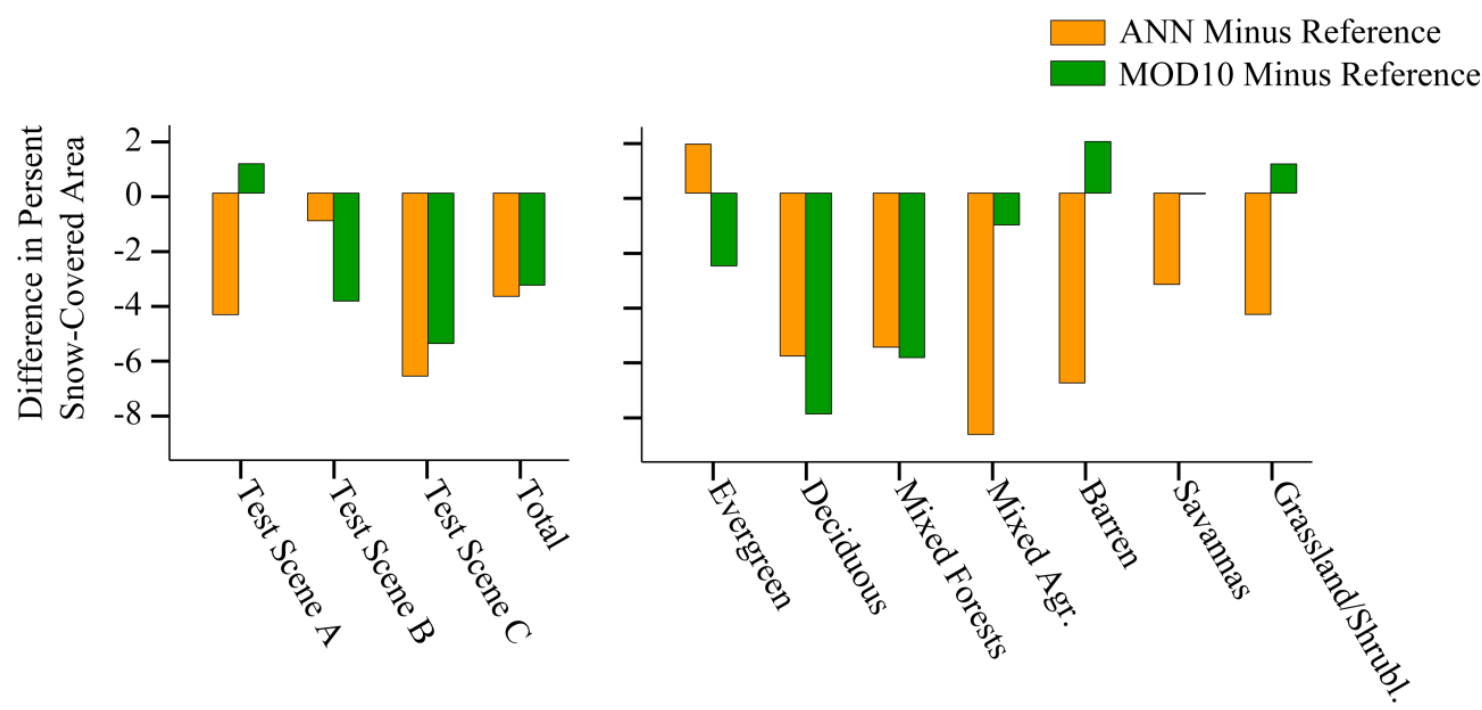

Fig. 9. Difference in percentage of snow-covered area.

The mapping accuracy of the ANN was also examined by calculating Root Mean Square Error (RMSE) and coefficient of determination $\left(\mathrm{R}^{2}\right)$ between ANN and reference snow fraction. RMSE was calculated as

$$
\mathrm{RMSE}=\sqrt{\frac{1}{1-\mathrm{n}} * \sum_{\mathrm{i}=1}^{\mathrm{n}}\left(\mathrm{x}^{\prime}-\mathrm{x}\right)^{2}}
$$

where $\mathrm{n}$ is the number of samples, $\mathrm{x}^{\prime}$ is the estimated FSC and $\mathrm{x}$ is the reference FSC. $\mathrm{R}^{2}$ is a measure of the correlation between the estimated and reference FSC and is the square of the Person correlation coefficient.

The agreement between the reference FSC and the ANN-estimated FSC was high with $\mathrm{R}^{2}$ ranging from 0.91 to 0.80 and the RMSE ranging between $10.39 \%$ and $13.30 \%$ (Table 6). RMSE between ANN FSC and reference FSC (10.39\%) was lowest over the non forested Labrador test scene. The two forested scenes had slightly higher but similar RMSE of $12.66 \%$ for Alberta and $12.75 \%$ for Michigan/Wisconsin. 
Table 6

RMSE and $\mathrm{R}^{2}$ for test scenes. RMSE and $\mathrm{R}^{2}$ between ANN FSC and reference FSC and between MOD10 FSC and reference FSC

\begin{tabular}{|l|c|c|c|c|c|c|c|c|}
\hline & \multicolumn{2}{|c|}{ Test Samples } & \multicolumn{2}{c|}{ Test Scene A } & \multicolumn{2}{c|}{ Test Scene B } & \multicolumn{2}{c|}{ Test Scene C } \\
\hline & $\mathrm{R}^{2}$ & RMSE (\%) & $\mathrm{R}^{2}$ & RMSE (\%) & $\mathrm{R}^{2}$ & RMSE (\%) & $\mathrm{R}^{2}$ & RMSE (\%) \\
\hline ANN & 0.80 & $13.30 \%$ & 0.89 & $10.39 \%$ & 0.89 & $12.66 \%$ & 0.91 & $12.75 \%$ \\
\hline MOD10 & n/a & n/a & 0.91 & $8.99 \%$ & 0.90 & $12.16 \%$ & 0.89 & $12.50 \%$ \\
\hline
\end{tabular}

The good agreement between the ANN FSC and the Landsat FSC can be seen through scatter plot graphs of estimated versus reference FSC (Figs. 10, 11, 12). While, overall agreement was high, the neural network appeared to overestimate snow fraction at low FSC and underestimate it at high FSC.
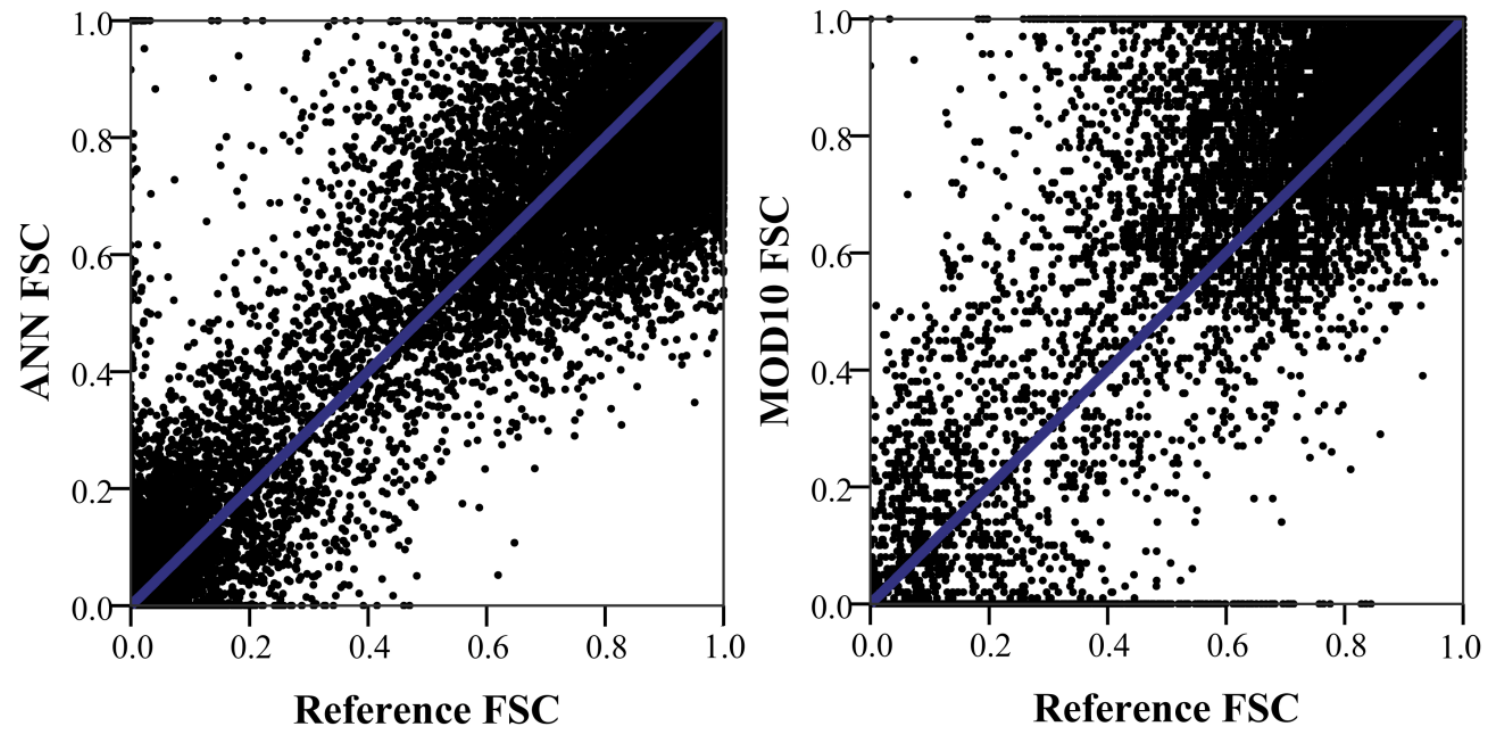

Fig. 10. Scatter plots of test scene A. Scatter plots showing ANN and MODIS FSC estimates with respect to reference FSC for test scene A. 

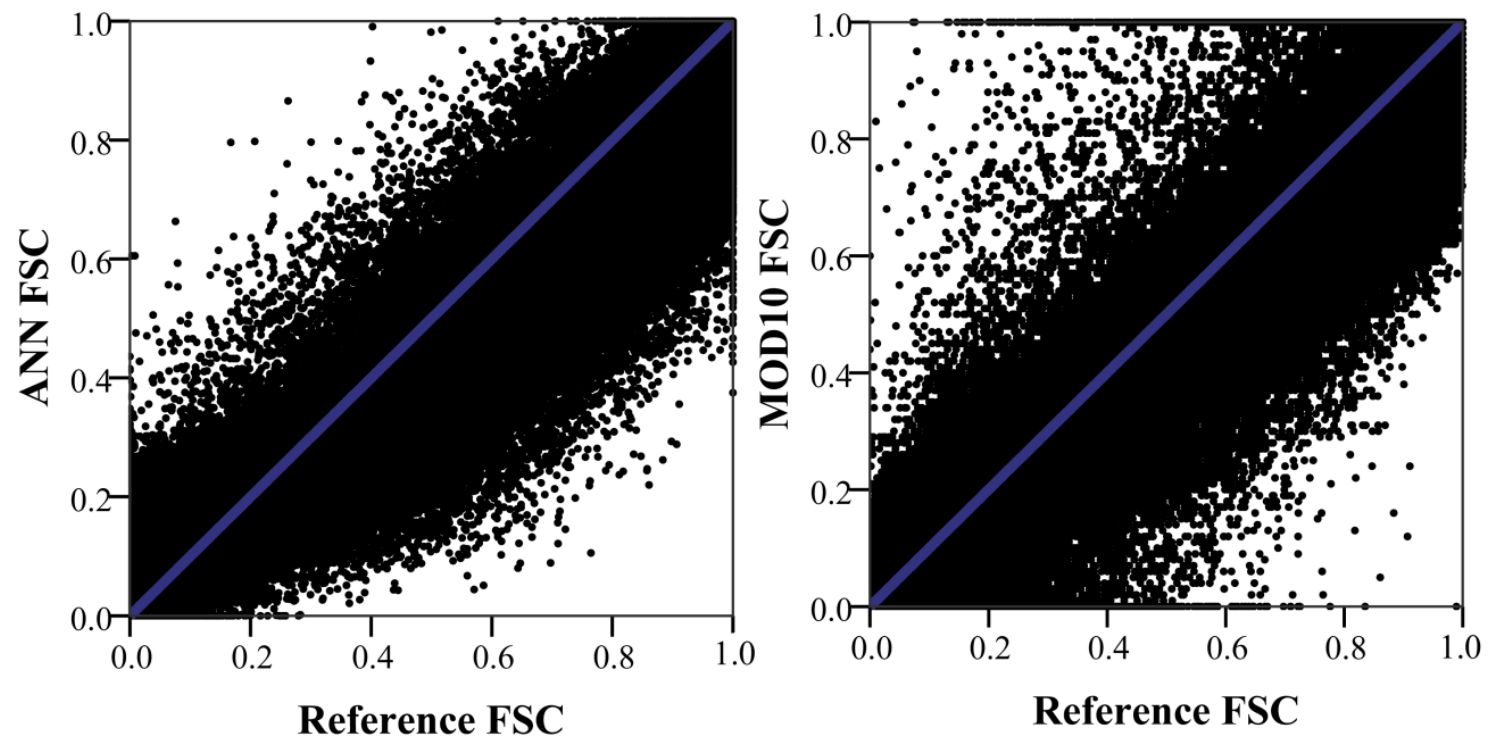

Fig. 11. Scatter plots of test scene B. Scatter plots showing ANN and MODIS FSC estimates with respect to reference FSC for test scene B.
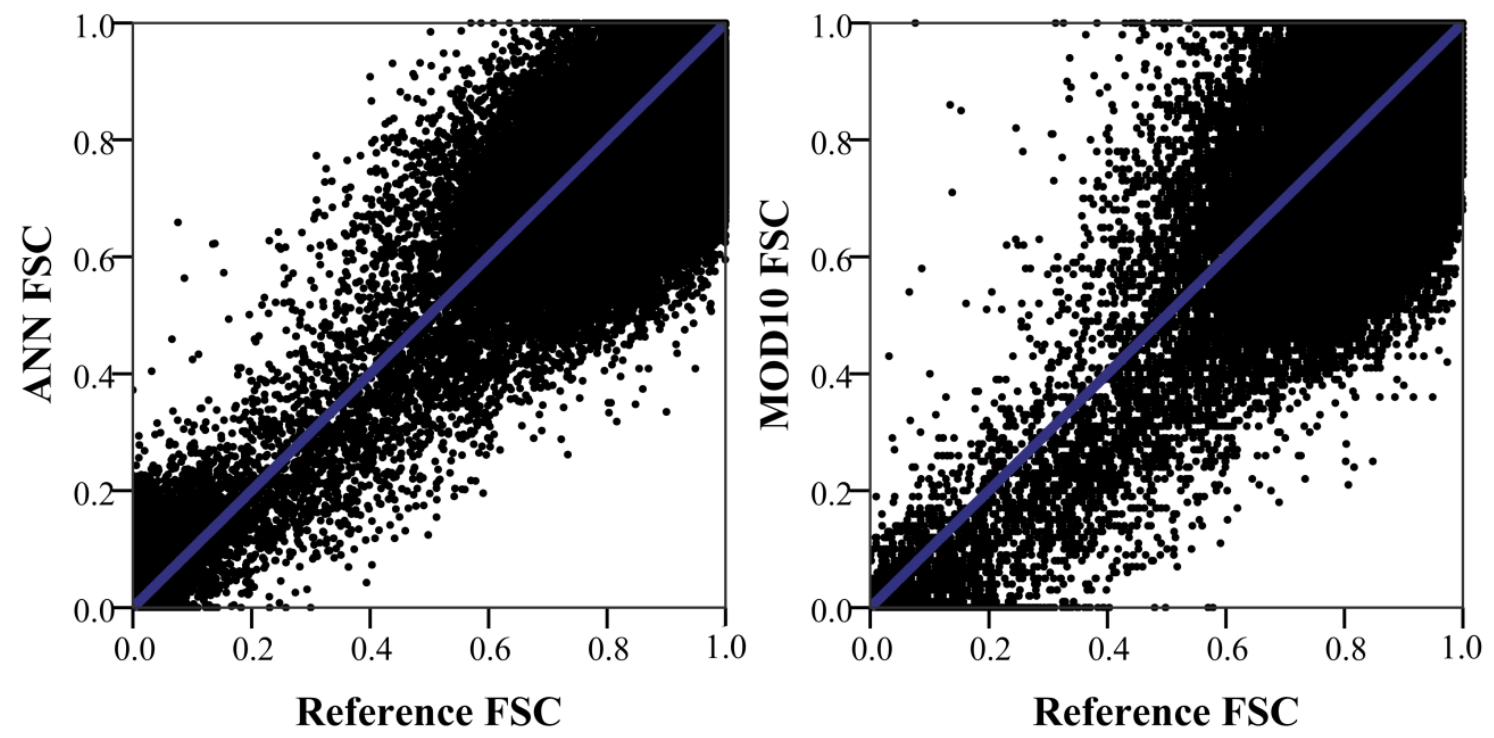

Fig. 12. Scatter plots of test scene C. Scatter plots showing ANN and MODIS FSC estimates with respect to reference FSC for test scene C. 
The underestimation of FSC is also evident by comparing reference and ANN snow fraction maps (Figs. 13, 14 and 15). The ANN FSC captured the spatial variability of snow cover successfully with the same areas having highest and lowest snow fraction in both ANN and reference FSC maps. Spatial variability of ANN FSC was least in the test scene over Michigan and Wisconsin (Fig. 15).

Differences between ANN and reference FSC were examined spatially by creating error maps (Figs. 16, 17, 18). Error maps for the ANN result were created by subtracting the reference snow fraction form the ANN snow fraction. Similarly, error maps for the MODIST snow fraction was created by subtracting the reference FSC from the MODIS FSC. These error maps illustrate areas where ANN underestimates snow as negative values, and where ANN overestimated - as positive. Histograms of the error indicated a nearly normal distribution of the differences between ANN and reference snow fraction. 


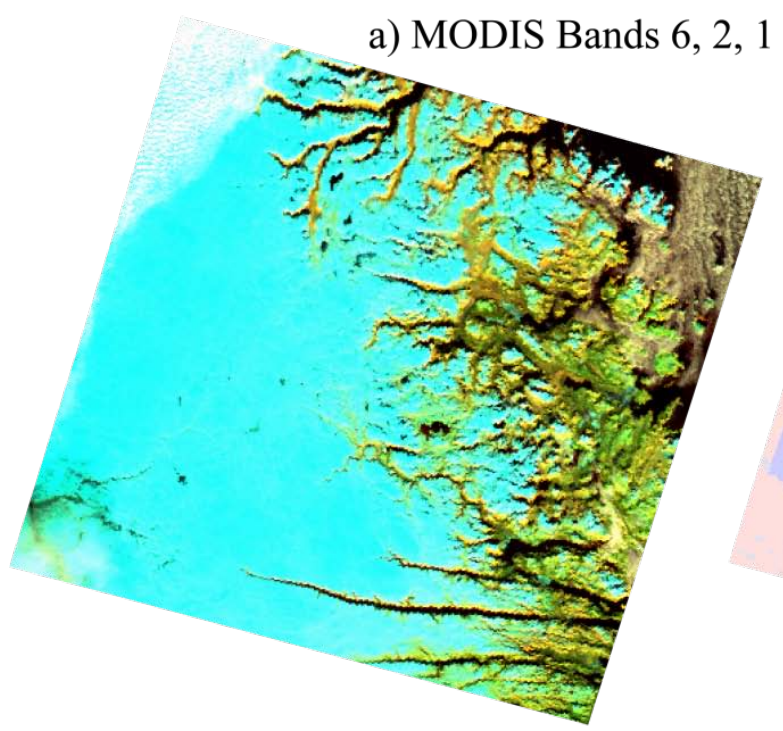

c) MOD10 FSC Map

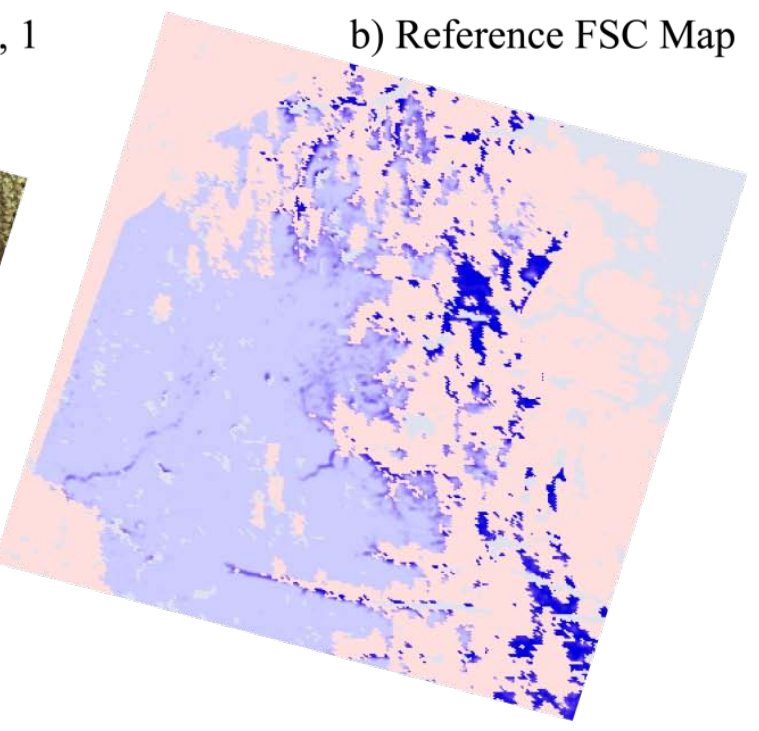

d) ANN FSC Map
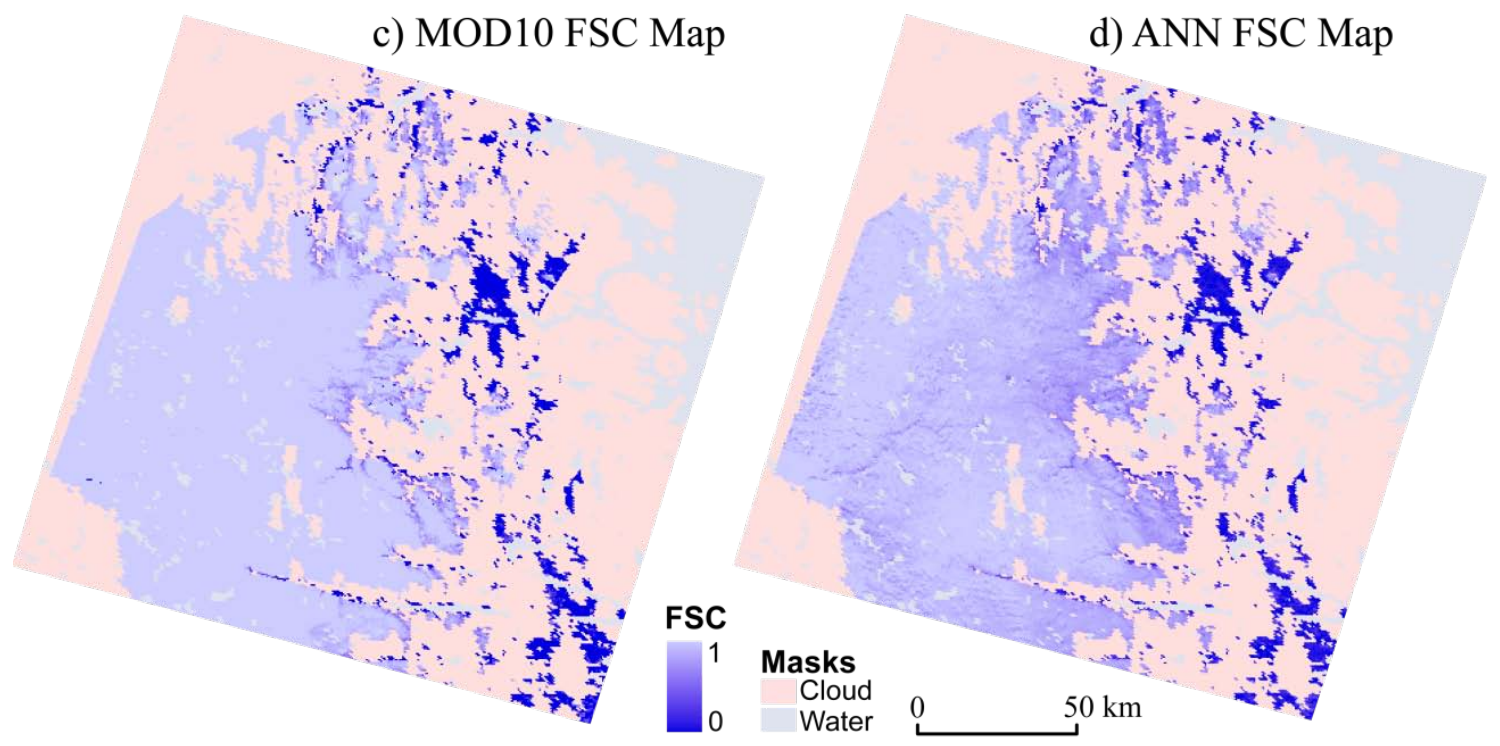

Fig. 13. ANN results of the network over Test Scene A. (a) A false-color image composite of MODIS bands 6, 2 and 1 as R, G and B shows snow as cyan colors; (b) reference snow map shows pixels covered with large snow fraction as light blue and snow-free pixels as dark blue; (c) MODIS and (d) neural network FSC maps. 

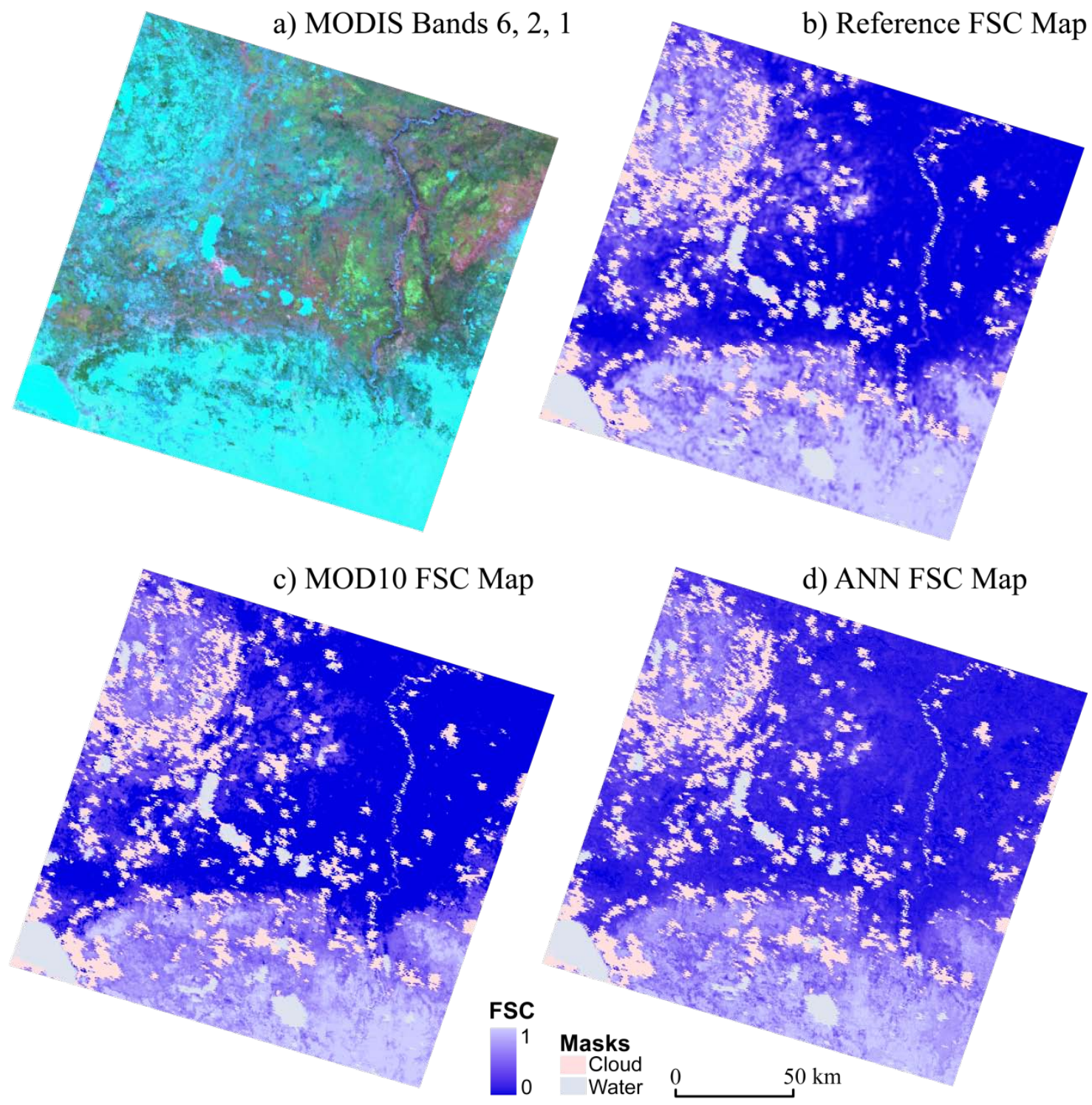

Fig. 14. ANN results of the network over Test Scene B. The displayed maps are patterned after those in Fig. 13. 
a) MODIS Bands 6, 2, 1
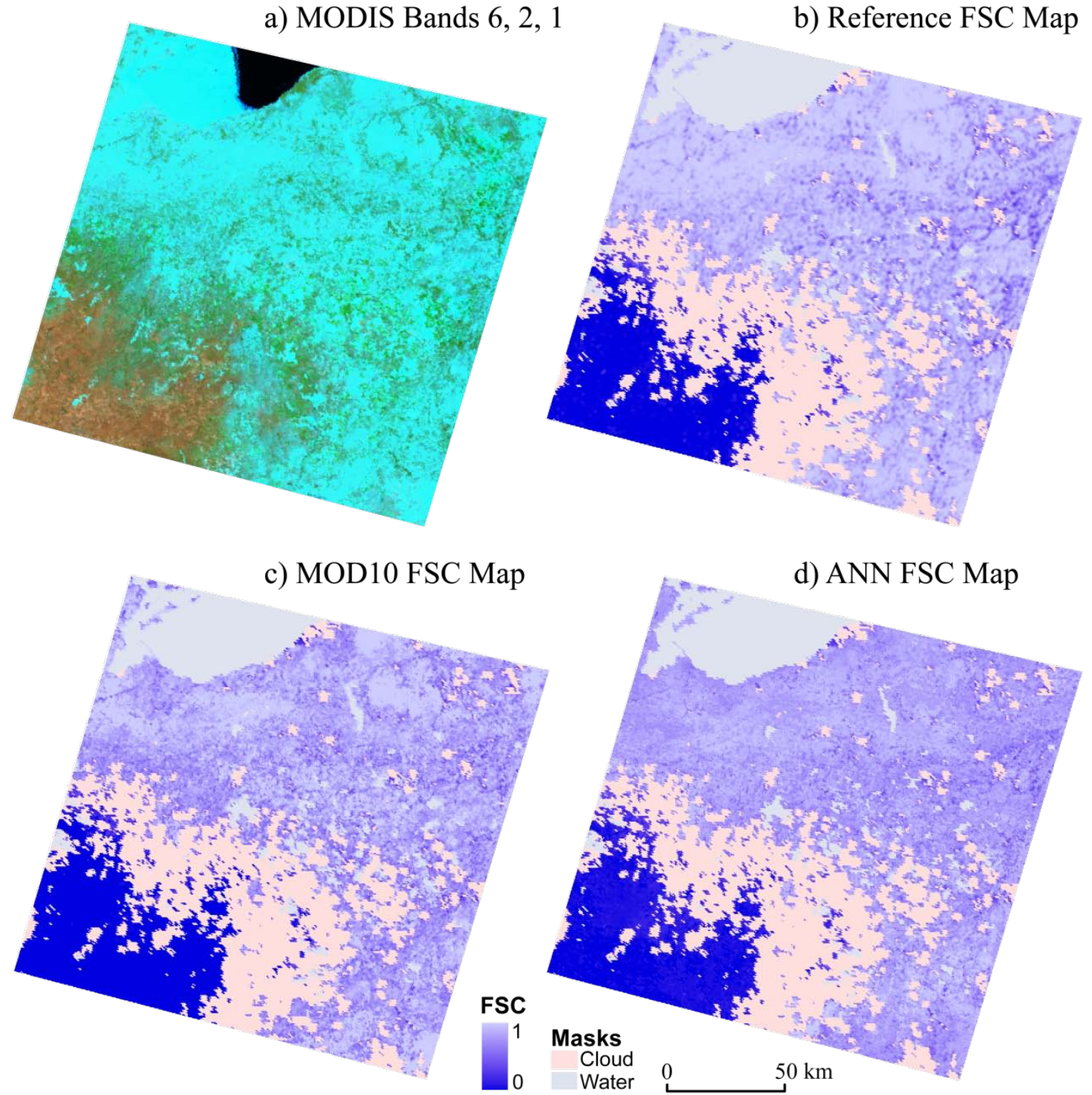

Fig. 15. ANN results of the network over Test Scene C. The displayed maps are patterned after those in Fig. 13. 


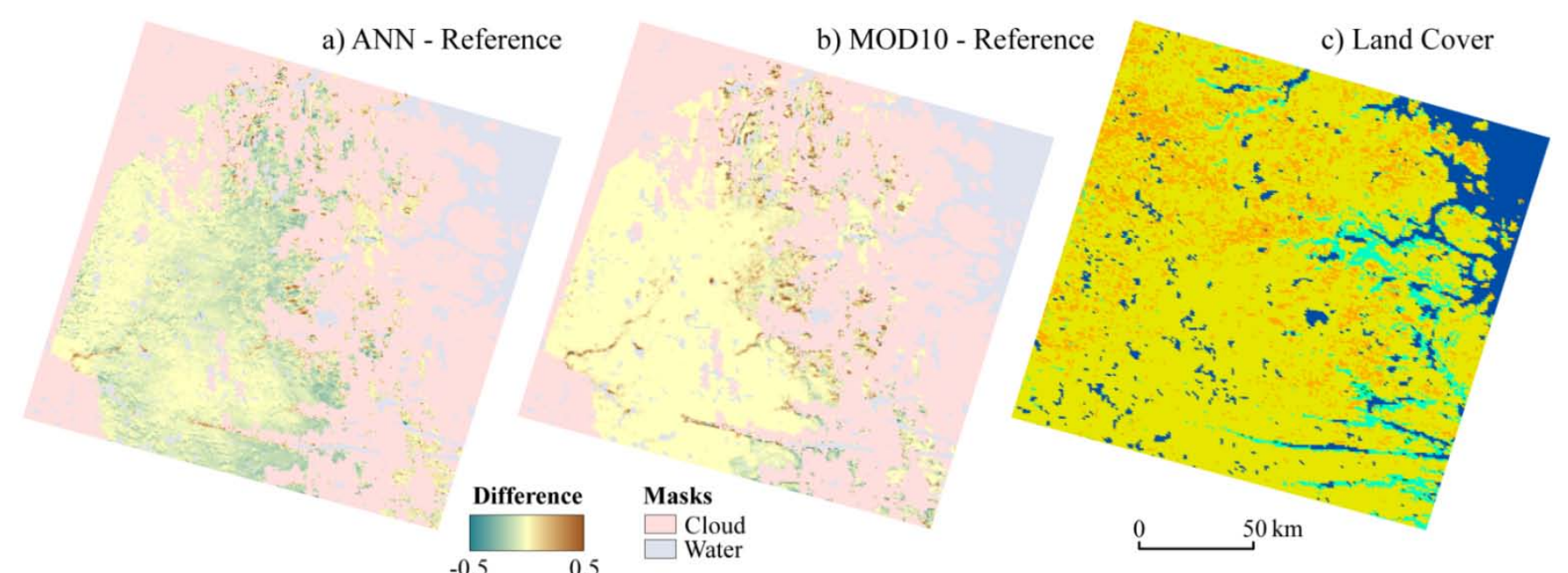

d) Histograms

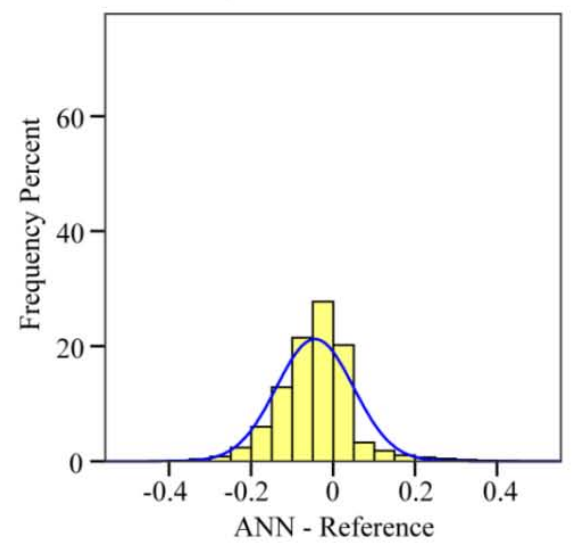

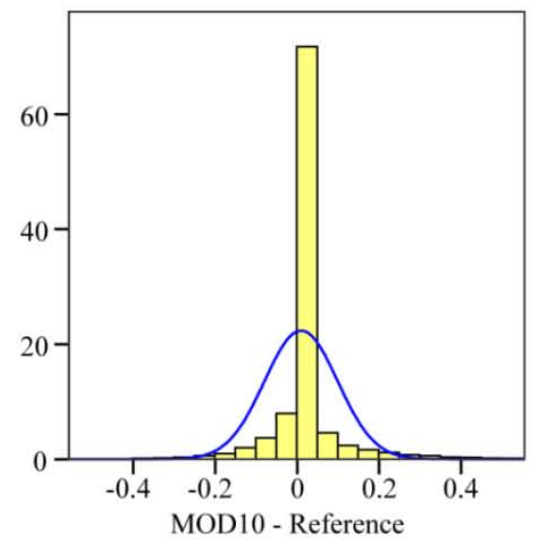

Land Cover

$\square$ Grasslands/Shrublands

$\square$ Tundra

Barren/Sparsely Vegetated

$\square$ Water

Fig. 16. Error maps of test scene A. Difference between estimated and reference snow fraction for (a) ANN and (b) MODIS; (c) land cover map of the test area; (d) histograms of the error distribution for ANN and MODIS. 

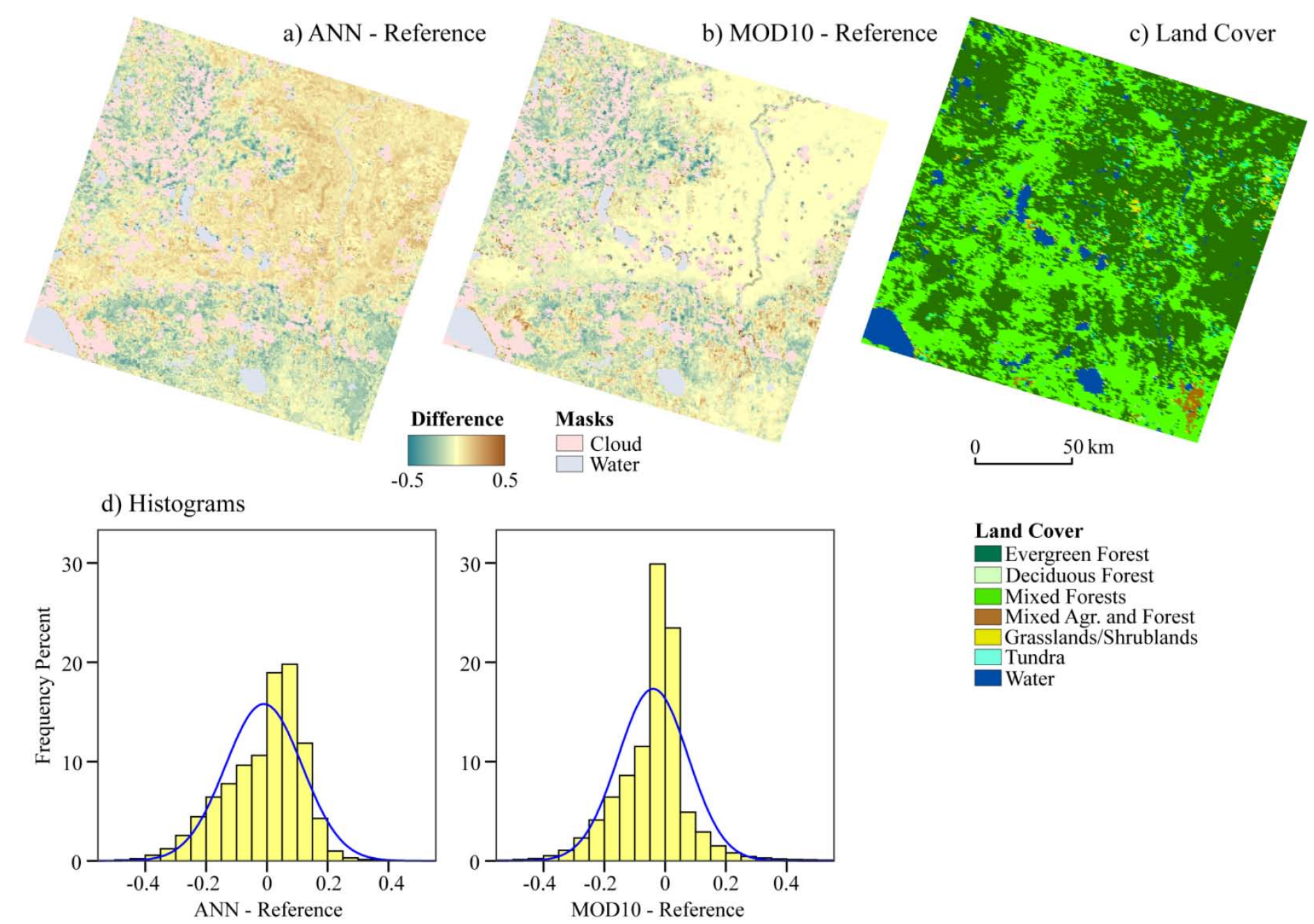
Land Cover
Evergreen Forest Deciduous Fores
Mixed Forests
Mixed Agr. and Forest
Grasslands/Shrublands
Tundra
Water

Fig. 17. Error maps of test scene B. The displayed maps and histograms are patterned after those in Fig. 16. 

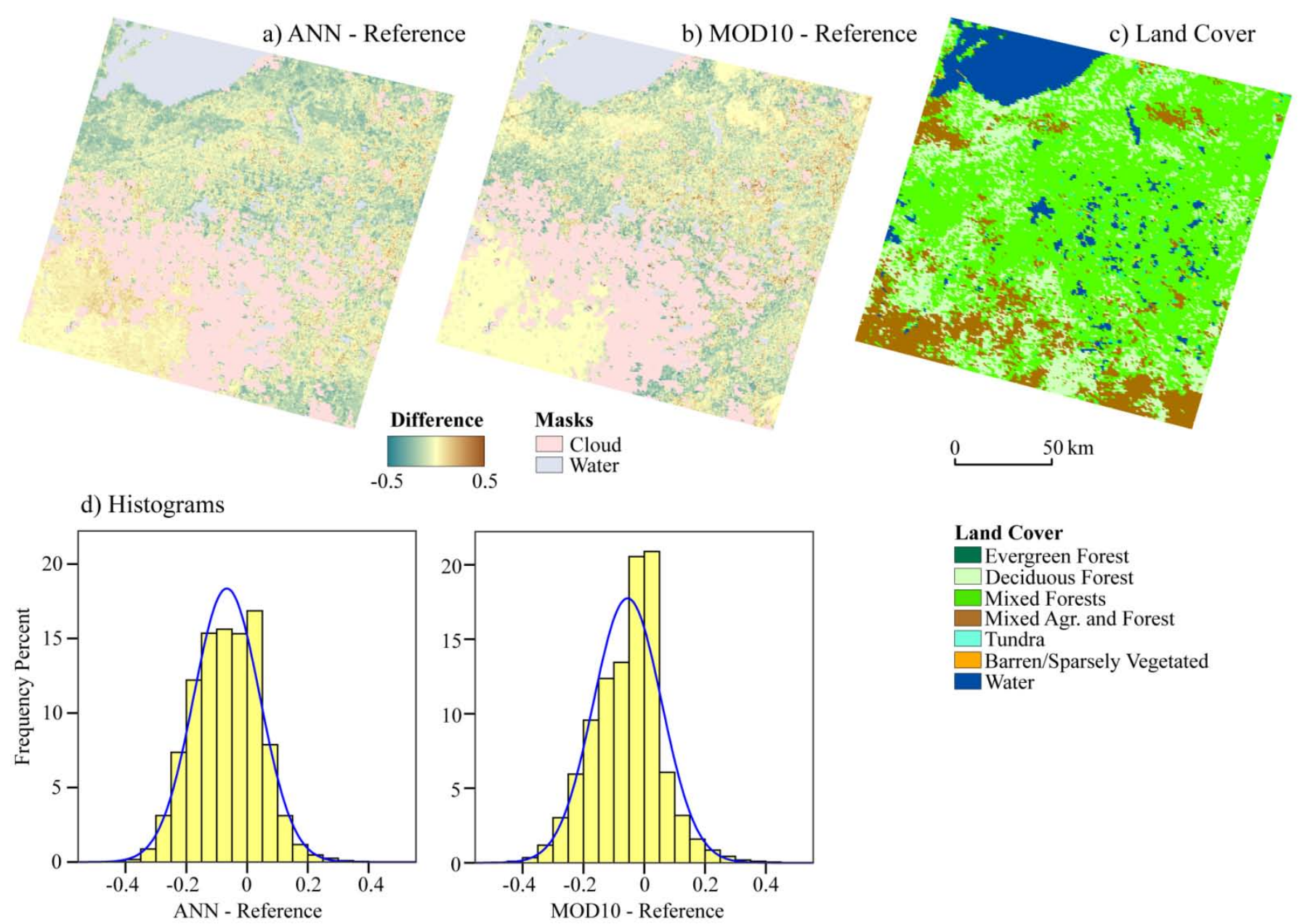

Fig. 18. Error maps of test scene C. The displayed maps and histograms are patterned after those in Fig. 16. 


\subsection{Mapping Accuracy by Land Cover}

The mapping accuracy as indicated by difference in snow-covered area between reference and ANN FSC was also analyzed for different land-cover categories (Table 7; Figs. 8 and 9). Evergreen forests had the least difference in percent snow-covered area (2\%) which means that for a $100 \mathrm{~km}^{2}$ the ANN estimated $2 \mathrm{~km}^{2}$ more snow cover than the reference. Evergreen forests were also the only land-cover category where ANN overestimated the total snow-cover extent. The difference in snow-cover extent between the ANN and reference snow-fraction maps was also low for savannas where for a 100 $\mathrm{km}^{2}$ ANN underestimated snow cover by $3 \mathrm{~km}^{2}$.

\section{Table 7}

Snow-covered area per land cover

\begin{tabular}{|c|c|c|c|c|c|}
\hline & \multicolumn{4}{|c|}{$\begin{array}{c}\text { Snow-Covered Area } \\
\left(\mathbf{k m}^{2}\right) /(\text { percent of total area) }\end{array}$} \\
\hline Test Scene & $\begin{array}{c}\text { Total } \\
\text { area } \\
\left(\mathbf{k m}^{2}\right)\end{array}$ & Reference & ANN & $\begin{array}{c}\text { MOD10 } \\
\text { (snow } \\
\text { fraction) }\end{array}$ & $\begin{array}{c}\text { MOD10 } \\
\text { (binary) }\end{array}$ \\
\hline Evergreen & 15,547 & $4,380 / 28$ & $4,658 / 30$ & $3,967 / 26$ & $6,888 / 44$ \\
\hline Deciduous & 4,981 & $3,528 / 71$ & $3,232 / 65$ & $3,127 / 63$ & $3,759 / 75$ \\
\hline $\begin{array}{c}\text { Mixed } \\
\text { Forests }\end{array}$ & 23,805 & $14,783 / 62$ & $13,445 / 56$ & $13,356 / 56$ & $17,354 / 73$ \\
\hline $\begin{array}{c}\text { Mixed } \\
\text { Agriculture }\end{array}$ & 3,644 & $1,921 / 53$ & $1,600 / 44$ & $1,879 / 52$ & $2,035 / 56$ \\
\hline Barren & 1,448 & $1,363 / 94$ & $1,263 / 87$ & $1,390 / 96$ & $1,414 / 98$ \\
\hline Savannas & 1,027 & $404 / 39$ & $370 / 36$ & $404 / 39$ & $462 / 45$ \\
\hline Grassland & 12,830 & $11,147 / 87$ & $10,580 / 82$ & $11,284 / 88$ & $11,444 / 89$ \\
\hline
\end{tabular}


RMSE and $\mathrm{R}^{2}$ were also calculated for the different land-cover categories (Table 8). The ANN FSC over Mixed Agriculture had the highest correlation with the reference FSC $\left(\mathrm{R}^{2}=0.97\right)$; however, it also had the largest RMSE (13.85\%). The lowest RMSE (10.32\%) was over Grasslands/shrublands. The forest land-cover categories had RMSEs ranging from $11.89 \%$ to $12.86 \%$ and $\mathrm{R}^{2}$ from 0.88 to 0.95 .

Table 8

RMSE and $\mathrm{R}^{2}$ per land cover

\begin{tabular}{|l|c|c|c|c|c|}
\hline & $\begin{array}{c}\text { Number of } \\
\text { samples }\end{array}$ & \multicolumn{2}{|c|}{ ANN } & \multicolumn{2}{c|}{ MOD10 } \\
\hline & & $\mathrm{R}^{2}$ & RMSE (\%) & $\mathrm{R}^{2}$ & RMSE (\%) \\
\hline Evergreen forests & 67,479 & 0.88 & 12.24 & 0.86 & 12.16 \\
\hline Deciduous forests & 21,617 & 0.95 & 11.89 & 0.95 & 12.32 \\
\hline Mixed forests & 103,320 & 0.90 & 12.86 & 0.90 & 12.95 \\
\hline Mixed agriculture & 15,817 & 0.97 & 13.85 & 0.97 & 7.47 \\
\hline Barren/sparsely vegetated & 6,283 & 0.61 & 12.31 & 0.74 & 7.48 \\
\hline Savannas & 4,456 & 0.91 & 13.80 & 0.91 & 13.72 \\
\hline Grasslands/shrublands & 55,686 & 0.89 & 10.32 & 0.90 & 9.12 \\
\hline
\end{tabular}




\section{DISCUSSION}

\subsection{Overall Performance of ANN}

The neural network was able to successfully map snow fraction using MODIS surface reflectance, NDSI, NDVI and land cover as inputs. Mapping accuracy of the three independent test scenes was good and the best performance was achieved over a test scene dominated by evergreen forests. The correlation between ANN and reference

snow fraction as measured by $\mathrm{R}^{2}$ was good. However, the ANN tended to underestimate the Landsat-derived FSC at higher snow fractions and overestimate them at lower snow fractions.

\subsection{Comparison to MODIS Snow-Cover Products}

The ANN FSC was also compared to the FSC provided as part of the MODIS/Terra Snow Cover Daily L3 Global 500m Grid (MOD10A1) product (Riggs et al., 2006) (Tables 5-8, Fig. 8-18) and to the binary snow cover product also provided in MOD10A1 (Fig. 8). The two products are distributed by the National Snow and Ice Data Center (NSIDC, 2009). Both the ANN and the snow-fraction MODIS product estimated the same percent (56\%) of the combined area of the test scenes as snow-covered which is $3 \%$ less than the reference which means that for a $100 \mathrm{~km}^{2}$ both the ANN and MODIS snow-fraction maps underestimate the snow-cover extent by $3 \mathrm{~km}^{2}$. For the Alberta test scene which had mainly evergreen forests, the neural network had estimated only $1 \%$ less snow than the reference, while the snow-fraction MODIS product had derived 4\% less. The ANN and snow-fraction MODIS results were most similar over the Michigan 
test scene which had mixed and deciduous forests and mixed agriculture land-cover categories. The differences between the two FSC methods were largest over the Labrador test scene which had mostly savannas and barren/sparsely vegetated landcovers categories. For that scene, the snow-fraction MODIS product overestimated the snow-covered area by $1 \%$ while the ANN underestimated it by $5 \%$. Notably, that is a training scene for the snow-fraction MODIS product (Salomonson \& Appel, 2004, 2006) and therefore the good agreement between the estimated by the snow-fraction MODIS method and the reference FSC could be expected.

With exception of the Labrador test scene the ANN RMSE were also comparable to the snow-fraction MODIS product. Based on the two test scenes not used in the developing of the MODIS FSC method, the ANN and the empirical NDSI approaches achieve similar FSC accuracy as measured by RMSE when compared to the reference Landsat snow maps. The correlation between the estimated and reference snow fraction was also comparable with $\mathrm{R}^{2}$ of both approaches for the three test scenes ranging between 0.89 and 0.91 .

Scatterplots of ANN-derived and reference snow fraction and MODIS and reference snow fraction (Figs. 11, 12, 13) show less scatter for the ANN FSC. This means a larger range in errors in the MODIS FSC product that in the ANN-derived FSC maps. Yet, the error maps and the histograms of the errors (Figs. 16, 17, 18) showed more pixels had snow-fraction errors close to 0 in the MODIS product that in the ANN FSC map.

Comparing the ANN and snow-fraction MODIS for different land covers showed that over the forested areas ANN was more accurate. For a $100 \mathrm{~km}^{2}$ of evergreen forests 
the MODIS snow-fraction map underestimated the snow-cover extent by $6 \mathrm{~km}^{2}$ while ANN overestimated it by $2 \mathrm{~km}^{2}$. Over deciduous forests, snow-fraction MODIS estimated $8 \mathrm{~km}^{2}$ less and ANN - $6 \mathrm{~km}^{2}$ less. Both methods calculated similar snowcovered area over mixed forests $-6 \mathrm{~km}^{2}$ less. Yet, the ANN performed slightly better for the total of $14,783 \mathrm{~km}^{2}$ of mixed forests, the ANN estimated $89 \mathrm{~km}^{2}$ more snowcover than the snow-fraction MODIS. For the non-forested areas snow-fraction MODIS mapped the snow-covered area more accurately that the ANN - for mixed agriculture, snow-fraction MODIS had estimated only $1 \mathrm{~km}^{2}$ less than the reference while ANN had estimated $9 \mathrm{~km}^{2}$ less. The binary snow-cover MODIS product consistently overestimated the snow-covered area (Fig. 8). The greatest overestimation was for forests while the snow-covered area over grasslands/shrublands and barren/sparsely vegetated was similar to the reference.

\subsection{Comparison to Linear Spectral Unmixing}

The overall mapping accuracy of the ANN snow-fraction maps was compared to the reported accuracies of linear spectral unmixing snow-fraction approaches. SnowFrac which has been developed and tested over Norway and Switzerland, has a reported $\mathrm{R}^{2}$ of 0.95 and 0.85 (Vikhamar \& Solberg, 2002). These are similar to the developed ANN FSC for which $\mathrm{R}^{2}$ of three independent test scenes was between 0.89 and 0.91 . The most recent study of linear mixture analysis for FSC mapping (Painter et al., 2009), reported an average RMS error of 5\%. Validation scenes were located in the Colorado Rocky Mountains, the Sierra Nevada of California, the headwaters of the Rio Grande, and the Himalayas. Due to topography barren areas, brush, meadows and alpine savannas were 
present at high altitudes while coniferous and deciduous forests were present at the lower elevations of the validation areas. However, the study did not report error analysis per land cover and due to the assumption of linear spectral mixing the method may not be performing well in forested areas.

\subsection{Error Analysis}

The better mapping accuracy of the ANN over forested areas than over nonforested areas vcan be attributed to the large percentage (42\%) of forested training pixels (Table 9). Evergreen, deciduous and mixed forests were considered as separate landcover categories (Fig. 7) and therefore each forest category was represented by a large number of training examples. The grassland pixels were dominated by high FSC so even small differences in snow-fraction result in large variations in snow-cover extent (Fig. 19). It should also be noted that nearly all of the grassland pixels in the three test scenes came from the Labrador test scene which was used during the development of the MODIS snow fraction method. 


\section{Table 9}

Number and percent training samples per land covers

\begin{tabular}{|l|c|c|}
\hline & $\begin{array}{c}\text { Number of } \\
\text { training samples }\end{array}$ & $\begin{array}{c}\text { Percent of } \\
\text { training samples }\end{array}$ \\
\hline Evergreen forests & 2,176 & 15 \\
\hline Deciduous forests & 910 & 6 \\
\hline Mixed forests & 3,144 & 21 \\
\hline Mixed agriculture & 2,472 & 17 \\
\hline Barren/sparsely vegetated & 219 & 1 \\
\hline Savannas & 2,258 & 15 \\
\hline Grasslands/shrublands & 2,818 & 19 \\
\hline Perm. Snow and Ice & 708 & 5 \\
\hline Wetlands & 88 & 1 \\
\hline Total & 14,793 & 100 \\
\hline
\end{tabular}




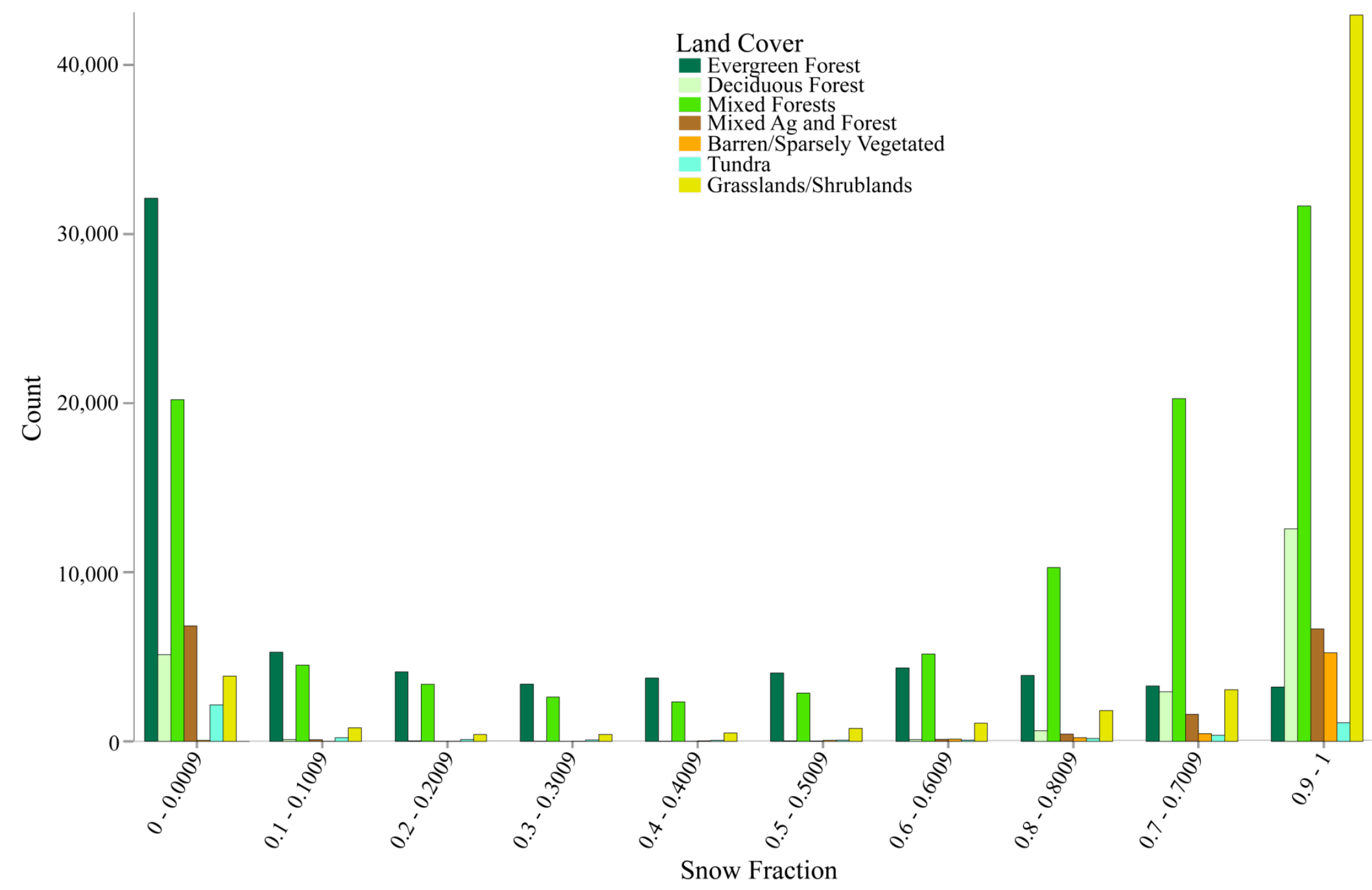

Fig. 19. Test points. Number of pixels in the three test scenes combined for each land cover and snow fraction categories. 


\section{CONCLUSIONS AND FUTURE DIRECTIONS}

In this study, a neural network trained with backpropagation successfully learned the relationship between MODIS snow fraction and surface reflectance in seven wavelength bands, NDSI, NDVI and land cover. The network was applied to scenes independent of those used for training and results were compared to reference Landsat snow maps and to the MODIS FSC product. The ANN performance across the test scenes and across different land cover types was comparable to the standard MODIS snow fraction product and other fractional snow-cover approaches.

ANN achieved the best result in terms of extent of snow-covered area over evergreen forests where it slightly overestimated the snow-cover extent. The developed neural network tended to underestimate in high FSC and overestimate in low FSC. ANN snow-fraction results compared favorably to the standard MODIS FSC product with the two methods estimating the same amount of total snow-covered area in the test scenes (56\% of the total area). However, both approaches underestimated the snow-cover extent compared to the reference FSC maps (59\% of the total area). In estimating the extent of snow-covered area the ANN was more accurate in forested areas than the snow-fraction MODIS product. The neural network approach to snow-fraction mapping compared well to the linear spectral unmixing approaches as well.

This was the first study that the authors were aware of training where an artificial neural network was trained to estimate snow-cover fraction. The network architecture employed was a traditional backpropagation feed-forward network. Improved snow- 
mapping accuracy may be obtained by developing a more sophisticated ANN. For examples, a combination of self-organizing maps, learning vector quantization and a Gaussian mixture model have been applied to estimate the subpixel abundance of urban surfaces from landsat ETM+ images (Lee \& Lathrop, 2006). Better snow-fraction mapping may also be achieved by including additional inputs such as tree-cover fraction, elevation or any of the MODIS thermal bands. 


\section{REFERENCES}

Arnfield, A.J. (2006). Micro- and mesoclimatology. Progress in Physical Geography, 30(5), 677-689.

Bales, R.C., Molotch, N.P., Painter, T.H., Dettinger, M.D., Rice, R., \& Dozier, J. (2006). Mountain hydrology of the western United States. Water Resources Research, 42, W08432.1- W08432.13.

Barnett, T.P., Adam, J.C., \& Lettenmaier, D.P. (2005). Potential impacts of a warming climate on water availability in snow-dominated regions. Nature, 438(7066), 303-309.

Basist, A., Garrett, D., Ferraro, R., Grody, N., \& Mitchell, K. (1996). A comparison between snow cover products derived from visible and microwave satellite observations. Journal of Applied Meteorology, 35(2), 163-177.

Berry, M.O. (1981). Snow and Climate. In D.M. Gray \& D.H. Male (Eds.), Handbook of Snow: Principles, Processes, Management \& Use. pp. 32-59.Toronto: Pergamon Press.

Chavez, P.S. (1988). An improved dark-object subtraction technique for atmospheric scattering correction of multispectral data. Remote Sensing of Environment, 24, 459-479.

Derksen, C., \& LeDrew, E. (2000). Variability and change in terrestrial snow cover: data acquisition and links to the atmosphere. Progress in Physical Geography, 24(4), 469-498.

Dickinson, R.E., Oleson, K.W., Bonan, G., Hoffman, F., Thornton, P., Vertenstein, M., Yang, Z.L., \& Zeng, X.B. (2006). The Community Land Model and its climate statistics as a component of the Community Climate System Model. Journal of Climate, 19(11), 2302-2324.

Douville, H., Chauvin, F., Planton, S., Royer, J.F., Salas-Melia, D., \& Tyteca, S. (2002). Sensitivity of the hydrological cycle to increasing amounts of greenhouse gases and aerosols. Climate Dynamics, 20(1), 45-68.

Dozier, J. (1989). Spectral signature of alpine snow cover from the Landsat Thematic Mapper. Remote Sensing of Environment, 28, 9-22. 
Dozier, J. (1992). Opportunities to improve hydrologic data. Reviews of Geophysics, 30(4), 315-331.

Dozier, J., Painter, T.H., Rittger, K., \& Frew, J.E. (2008). Time-space continuity of daily maps of fractional snow cover and albedo from MODIS. Advances in Water Resources, 31(11), 1515-1526.

Filippi, A.M., \& Jensen, J.R. (2006). Fuzzy learning vector quantization for hyperspectral coastal vegetation classification. Remote Sensing of Environment, 100(4), 512-530.

Foody, G.M., Lucas, R.M., Curran, P.J., \& Honzak, M. (1997). Non-linear mixture modelling without end-members using an artificial neural network. International Journal of Remote Sensing, 18(4), 937-953.

Foppa, N., Wunderle, S., Hauser, A., Oesch, D., \& Kuchen, F. (2004). Operational subpixel snow mapping over the Alps with NOAA AVHRR data. Annals of Glaciology, 38, 245-252.

GLCF (2009). Global Land Cover Facility. http://glcf.umiacs.umd.edu/index.shtml

Guilfoyle, K.J., Althouse, M.L., \& Chang, C.I. (2001). A quantitative and comparative analysis of linear and nonlinear spectral mixture models using radial basis function neural networks. IEEE Transactions on Geoscience and Remote Sensing, 39(10), 2314-2318.

Hall, D.K., Foster, J.L., Salomonson, V.V., Klein, A.G., \& Chien, J.Y.L. (2001). Development of a technique to assess snow-cover mapping errors from space. IEEE Transactions on Geoscience and Remote Sensing, 39(2), 432-438.

Hall, D.K., Kelly, R.E.J., Foster, J.F., \& Chang, A.T.C. (2005). Estimation of Snow Extent and Snow Cover Properties. In M.G. Anderson (Ed.), Encyclopedia of Hydrological Sciences (Chapter 55, pp. 1-19). US: John Wiley \& Sons Inc.

Hall, D.K., Riggs, G.A., \& Salomonson, V.V. (1995). Development of methods for mapping global snow cover using Moderate Resolution Imaging Spectroradiometer data. Remote Sensing of Environment, 54(2), 127-140.

Hall, D.K., Riggs, G.A., Salomonson, V.V., DiGirolamo, N.E., \& Bayr, K.J. (2002). MODIS snow-cover products. Remote Sensing of Environment, 83(1-2), 181194.

Haykin, S. (1999). Neural Networks: A Comprehensive Foundation Upper Saddle River, NJ: Prentice Hall. 
Hodges, J. (2002). MODIS MOD12 Land Cover and Land Cover Dynamics Products User Guide. http://www-modis.bu.edu/landcover/userguidelc/

Hongen, Z., \& Suhong, L. (2004). Moderate fraction snow mapping in Tibetan Plateau. Proceedings of IGARSS '04 (pp. 3700-3701).

Jensen, J.R. (2005). Introductory Digital Image Processing: A Remote Sensing Perspective. Upper Saddle River, NJ: Pearson Prentice Hall.

Kaufman, Y.J., Kleidman, R.G., Hall, D.K., Martins, J.V., \& Barton, J.S. (2002). Remote sensing of subpixel snow cover using 0.66 and $2.1 \mathrm{mu}$ m channels. Geophysical Research Letters, 29(16), 28.1-28.4.

Kaufmann, Y.J., A. E. Wald, L. A. Remer, B.-C. Gao, R.-R. Li, a., \& Flynn, L. (1997). The MODIS 2.1-mm Channel-Correlation with Visible Reflectance for Use in Remote Sensing of Aerosol. IEEE Transactions on Geoscience and Remote Sensing, 35(5), 1286-1298.

Klein, A.G., Hall, D.K., \& Riggs, G.A. (1998). Improving snow cover mapping in forests through the use of a canopy reflectance model. Hydrological Processes, 12(10-11), 1723-1744.

König, M., Winther, J.-G., \& Isaksson, E. (2001). Measuring Snow and Glacier Ice Properties From Satellite. Reviews of Geophysics, 39(1), 1-27.

Lamoureux, S.F., McDonald, D.M., Cockburn, J.M.H., Lafreniere, M.J., Atkinson, D.M., \& Treitz, P. (2006). An incidence of multi-year sediment storage on channel snowpack in the Canadian High Arctic. Arctic, 59(4), 381-390.

Lee, S., \& Lathrop, R.G. (2006). Subpixel analysis of Landsat ETM+ using SelfOrganizing Map (SOM) neural networks for urban land cover characterization. IEEE Transactions on Geoscience and Remote Sensing, 44(6), 1642-1654.

Lemke, P., J. Ren, R.B. Alley, I. Allison, J. Carrasco, G. Flato, Y. Fujii, G. Kaser, P. Mote, and, R.H.T., \& Zhang, T. (2007). Observations: changes in snow, sce and frozen ground. In S. Solomon, D. Qin, M. Manning, Z. Chen, M. Marquis, K.B. Averyt, M.T. and \& H.L. Miller (Eds.), Climate Change 2007: The Physical Science Basis. Contribution of Working Group I to the Fourth Assessment Report of the Intergovernmental Panel on Climate Change. Cambridge, UK: Cambridge University Press.

Liston, G.E. (1999). Interrelationships among snow distribution, snowmelt, and snow cover depletion: Implications for atmospheric, hydrologic, and ecologic modeling. Journal of Applied Meteorology, 38(10), 1474-1487. 
Marshall, S., Roads, J.O., \& Glatzmaier, G. (1994). Snow hydrology in a generalcirculation model. Journal of Climate, 7(8), 1251-1269.

Mejia, Y., Ghedira, H., Mahani, S., \& Khanbilvardi, R. (2008). Robust neural network system design for detecting and estimating snowfall from the Advanced Microwave Sounding Unit. Journal of Applied Remote Sensing, 2.

Metsamaki, S.J., Anttila, S.T., Markus, H.J., Vepsalainen, J.M., \& Bj (2005). A feasible method for fractional snow cover mapping in boreal zone based on a reflectance model. Remote Sensing of Environment, 95(1), 77-95.

NASA (2009a). Land Processes Distributed Active Archive Center https://lpdaac.usgs.gov/

NASA (2009b). Landsat 7. Science Data Users Handbook http://landsathandbook.gsfc.nasa.gov/handbook.html

NASA (2009c). MODIS Web http://modis.gsfc.nasa.gov/

Niu, G.Y., \& Yang, Z.L. (2007). An observation-based formulation of snow cover fraction and its evaluation over large North American river basins. Journal of Geophysical Research-Atmospheres, 112(D21). D21101.1- D21101.14.

NOAA (2009). IMS daily Northern Hemisphere snow and ice analysis at $4 \mathrm{~km}$ and 24 km resolution http://nsidc.org/data/g02156.html

Nolin, A.W., \& Dozier, J. (1993). Estimating snow grain-size using AVIRIS data. Remote Sensing of Environment, 44(2-3), 231-238.

NSIDC (2009). National Snow and Ice Data Center. Distributed Active Archive Center http://nsidc.org/daac/

Painter, T.H., Dozier, J., Roberts, D.A., Davis, R.E., Green, R.O., \& Le (2003). Retrieval of subpixel snow-covered area and grain size from imaging spectrometer data. Remote Sensing of Environment, 85(1), 64-77.

Painter, T.H., Rittger, K., McKenzie, C., Slaughter, P., Davis, R.E., \& Dozier, J. (2009). Retrieval of subpixel snow covered area, grain size, and albedo from MODIS. Remote Sensing of Environment, 113(4), 868-879.

Prestrud, P. (2007). Why are Snow and Ice Important to Us? In. Global Outlook for Ice and Snow (pp. 19-28). Oslo: Center for International Climate and Environmental Research 
Priddy, K.L., \& Keller, P.E. (2005). Artificial Neural Networks: An Introduction (SPIE Tutorial Texts in Optical Engineering, Vol. TT68). Bellingham, WA: SPIE Publications

Randall, D.A., Cess, R.D., Blanchet, J.P., Chalita, S., Colman, R., Dazlich, D.A., Delgenio, A.D., Keup, E., Lacis, A., Letreut, H., Liang, X.Z., McAvaney, B.J., Mahfouf, J.F., Meleshko, V.P., Morcrette, J.J., Norris, P.M., Potter, G.L., Rikus, L., Roeckner, E., Royer, J.F., Schlese, U., Sheinin, D.A., Sokolov, A.P., Taylor, K.E., Wetherald, R.T., Yagai, I., \& Zhang, M.H. (1994). Analysis of snow feedback in 14 General Circulation Models. Journal of Geophysical ResearchAtmospheres, 99(D10), 20757-20771

Rango, A. (1996). Spaceborne remote sensing for snow hydrology application. Hydrological Sciences, 41. 477-494.

Riggs, G.A., Hall, D.K., \& Salomonson, V.V. (2006). MODIS Snow Products User Guide to Collection 5. http://modis-snow-ice.gsfc.nasa.gov/sug_c5.pdf

Robinson, D.A., Dewey, K.F., \& Heim, R.R. (1993). Global snow cover monitoring - an update. Bulletin of the American Meteorological Society, 74, 1689-1696.

Roesch, A., Wild, M., Gilgen, H., \& Ohmura, A. (2001). A new snow cover fraction parametrization for the ECHAM4 GCM. Climate Dynamics, 17(12), 933-946.

Romanov, P., Tarpley, D., Gutman, G., \& Carroll, T. (2003). Mapping and monitoring of the snow cover fraction over North America. Journal of Geophysical ResearchAtmospheres, 108(D16). 14.1-14.15.

Rosenthal, W., \& Dozier, J. (1996). Automated mapping of montane snow cover at subpixel resolution from the Landsat Thematic Mapper. Water Resources Research, 32(1), 115-130.

Salomonson, V.V., \& Appel, I. (2004). Estimating fractional snow cover from MODIS using the normalized difference snow index. Remote Sensing of Environment, 89(3), 351-360.

Salomonson, V.V., \& Appel, I. (2006). Development of the Aqua MODIS NDSI fractional snow cover algorithm and validation results. Ieee Transactions on Geoscience and Remote Sensing, 44(7), 1747-1756.

Schowengerdt, R.A. (1997). Remote Sensing: Models and Methods for Image Processing. San Diego, CA: Academic Press. 
Serreze, M.C., Clark, M.P., \& Frei, A. (2001). Characteristics of large snowfall events in the montane western United States as examined using snowpack telemetry (SNOTEL) data. Water Resources Research, 37(3), 675-688.

Shabanov, N.V., Lo, K., Gopal, S., \& Myneni, R.B. (2005). Subpixel burn detection in Moderate Resolution Imaging Spectroradiometer 500-m data with ARTMAP neural networks. Journal of Geophysical Research-Atmospheres, 110(D3). D03111.1- D03111.17

Shi, J. (1999). Estimating snow fraction using AVIRIS simulated ASTER image in alpine regions. Proceedings of IGARSS '99 (pp. 1795-1797).

Simpson, J.J., \& McIntire, T.J. (2001). A recurrent neural network classifier for improved retrievals of areal extent of snow cover. IEEE Transactions on Geoscience and Remote Sensing, 39(10), 2135-2147.

Simpson, J.J., Stitt, J.R., \& Sienko, M. (1998). Improved estimates of the areal extent of snow cover from AVHRR data. Journal of Hydrology, 204(1-4), 1-23.

Sirguey, P., Mathieu, R., \& Arnaud, Y. (2009). Subpixel monitoring of the seasonal snow cover with MODIS at $250 \mathrm{~m}$ spatial resolution in the Southern Alps of New Zealand: Methodology and accuracy assessment. Remote Sensing of Environment, 113(1), 160-181.

Stephens, J., Adams, E., Huo, X., Dent, J., Hicks, J., \& McCarty, D. (2002). Use of Neural Networks in Avalanche Hazard Forecasting. International Snow Science Workshop: WestWide Avalanche Network http://www.avalanche.org/ moonstone/issw\%2094\%27/use\%20of\%20neural\%2 0networks\%20in\%20avalanche\%20hazard\%20forecasting.htm

Tatem, A.J., Lewis, H.G., Atkinson, P.M., \& Nixon, M.S. (2002). Super-resolution land cover pattern prediction using a Hopfield neural network. Remote Sensing of Environment, 79(1), 1-14.

Tedesco, M., Pulliainen, J., Takala, M., Hallikainen, M., \& Pampaloni, P. (2004). Artificial neural network-based techniques for the retrieval of SWE and snow depth from SSM/I data. Remote Sensing of Environment, 90(1), 76-85

Vermonte, E.F., \& Kotchenova, S.Y. (2008). MOD09 (Surface Reflectance) User’s Guide, Version 1.1. http://modissr.ltdri.org/MAIN_SURFACE_PRODUCTAND\%20USER\%20GUIDE/MOD09 _UserGuide.pdf 
Vikhamar, D., \& Solberg, R. (2002). Subpixel mapping of snow cover in forests by optical remote sensing. Remote Sensing of Environment, 84(1), 69-82.

Vikhamar, D., \& Solberg, R. (2003). Snow-cover mapping in forests by constrained linear spectral unmixing of MODIS data. Remote Sensing of Environment, 88(3), 309-323.

Wolfe, R.E. (2006). MODIS Geolocation Earth Science Satellite Remote Sensing. Berlin: Springer 


\section{APPENDIX A}

MATLAB program for training ANN

function net $=$ train_net

\%inputs has 9 columns \%columns 1-7 - MODIS reflectance bands \%column 8-9 - indices (NDSI, NDVI)

\%read input and target otput

inputs = textread (' $\mathrm{C}: \backslash$ geogtmp $\backslash A N N \backslash \bmod \cdot$ dat $\left.^{\prime}\right)$;

$\mathrm{p}=$ inputs' $^{\prime}$;

targets = textread ( ' $\mathrm{c}: \backslash$ geogtmp $\backslash A N N \backslash f \mathrm{fc}$. dat' $)$;

$\mathrm{t}=$ targets';

\%read indeces of sampels used for training, validation and test

train_in = textread (' $\mathrm{C}: \backslash$ geogtmp $\backslash A N N \backslash$ ind_train.txt');

val in = textread ( ' $c$ : \geogtmp \ANN\ind val.txt');

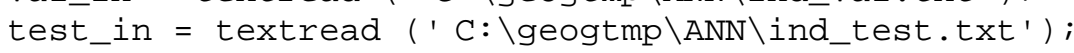

\%Specify numebr of hidden neurons

numHiddenNeurons $=20$;

\section{\%Normalize}

$[p n, p s]=\operatorname{mapminmax}(p,-1,1)$;

$[\mathrm{tn}, \mathrm{ts}]=\operatorname{mapminmax}(\mathrm{t},-1,1)$;

\%Save normalization settings so they can be refered when using the network net_ps = ' C: \geogtmp \ANN\net_ps';

save(net_ps, 'ps');

net_ts = ' c: \geogtmp \ANN\net_ts';

save(net_ts, 'ts'); 
\%Create Network

net $=$ newff $(p n, t n$, numHiddenNeurons, $\{$ 'tansig', 'purelin' $\}, \ldots$

'trainlm', 'learngdm', ...

'mse', \{'fixunknowns', 'removeconstantrows'\}, ...

\{'removeconstantrows'\}, 'dividerand');

\%specify indeces of sampels used for training, validation and test net.divideParam.trainInd = train_in;

net. divideParam. valind = val in:

net.divideParam.testInd = test_in;

\% Train Network

$[$ net, $\mathrm{tr}]=\operatorname{train}($ net $, \mathrm{pn}, \mathrm{tn})$;

\%Save Network

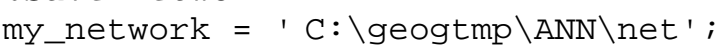

save (my_network, 'net');

end 


\section{APPENDIX B}

MATLAB program for using the trained ANN

function use_net

\%inputs has 10 columns - columns 1-7 - MODIS reflectance bands; column 8-9 - indices (NDSI, NDVI) \%column 10 - land cover

\%read input

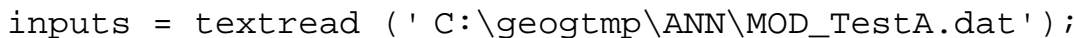

\%load the saved ANN and the input/output normalization

load ' C: \geogtmp \ANN\net' ;

load ' C: \geogtmp \ANN\net_ps',

load ' $C: \backslash g e o g t m p \backslash A N N \backslash n e t \_t s '$ '

\%normalize input

pnew = inputs'

pnew $=$ mapminmax $\left({ }^{a p p l y '}\right.$, pnew, net_ps $)$;

\%simulate ANN and reverse-normalize the output

anew $=\operatorname{sim}($ net, pnew $)$;

anew $=$ mapminmax ('reverse', anew, net_ts);

\%write output to file

outputs = anew';

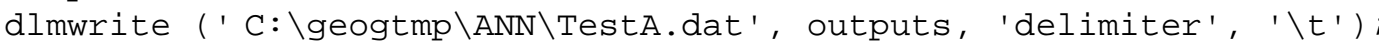

end 
VITA

Name: Iliyana Dancheva Dobreva

Address: Texas A\&M University

707G O\&M Building, TAMU Mail Stop 3147

College Station, TX 77843

Academic Background:

MS, Geography (2009), Texas A\&M University, College Station, TX

BA, Geography (2005), Concord University, Athens, WV

Research Interests

Glaciology, Remote Sensing, Machine Learning

Experience:

Graduate Teaching Assistant - (Aug 2007 - May 2008, Aug 2008 - Dec 2009),

Department of Geography, Texas A\&M Univ., College Station, TX

Graduate Research Assistant (June 2008 - Aug 2008), Department of Geography, Texas A\&M Univ., College Station, TX

\section{Publication}

Filippi, A. M., Brannstrom, C. Dobreva, I, Cairns, D. M. and D. Kim. (2009). Unsupervised Fuzzy ARTMAP Classification of Hyperspectral Hyperion Data for Savanna and Agriculture Discrimination in the Brazilian Cerrado, GIScience \& Remote Sensing. 46(1), 1-23.

Filippi, A. M., Dobreva, I., Klein, A., and Jensen, J. R. (In Press). Self-Organizing Mapbased Applications in Remote Sensing. Self-Organizing Maps. Vienna, Austria, EU: IN-TECH. ISBN978-953-7619-X-X.

\section{Poster Presentations}

Dobreva, I. and A.G. Klein. (2009).Artificial Neural Networks Approach to Fractional Snow Cover Mapping. $66^{\text {th }}$ Eastern Snow Conference, July 9-11 2009, Niagara on the Lake, Ontario, Canada

Dobreva, I. and A.G. Klein. (2008/2009). Fractional Snow Cover Mapping through Artificial Neural Network Analysis of MODIS Surface Reflectance. Annual meeting of the Southwestern Division of the Association of American Geographers (2008), San Marcus, Texas; Annual meeting of the Association of American Geographers (2009), Las Vegas, Nevada

\section{Awards}

David Hewitt Miller awards for best student poster at the 66th Eastern Snow

Conference, July 9-11 2009, Niagara on the Lake, Ontario, Canada 